

\section{About the journal}

Medicine Updates journal Port Said (MUJPS) is a double-blind peer review journal published quarterly-annually. Authors are invited to submit their work on any topic of wide spectrum coverage including; medicine, surgery, public health and epidemiology. Submission of articles is on understanding that the articles has not been previously published in any other form and is not accepted for publication elsewhere.

\section{Aim and Vision}

Medicine Updates journal the scientific journal of the faculty of medicine Port Said University hopes that the publish outstanding scientific research at the local, regional and international levels.

\section{Mission and scope}

Medicine Updates journal the scientific journal of the faculty of medicine Port Said University is characterized by the publication of distinguished medical scientific researches based on national and international publication standards in the following medical areas:

\section{Anesthesia and intensive care}

\section{Cardiology}

Cardiothoracic surgery

Chest diseases

Clinical pathology

Dermatology and andrology

Diagnostic and interventional radiology 
$>$ Ear, nose and throat

$>$ Emergency medicine

Endocrinology

Family medicine

Forensic medicine and clinical toxicology

Gastroenterology and hepatology

$>$ General surgery

$>$ Geriatric medicine

$>$ Hematology

$>$ Histology

$>$ Human anatomy and embryology.

$>$ Internal medicine

Medical biochemistry and molecular biology

Medical education

Medical parasitology

Medical pharmacology

Microbiology and immunology

Nephrology

Neuropsychiatry

Neurosurgery

Obstetrics and gynecology

Oncology and nuclear medicine

Ophthalmology

Orthopedic surgery

Pathology 


\section{Pediatric and neonatology}

Pediatric surgery

Physiology

Plastic surgery

Public health and industrial medicine

Rheumatology and rehabilitation

Tropical

Tumor surgery

Uro-surgery

Vascular surgery

\section{Editorial Board}

- Prof. dr. Khalid Sabry Salama (Editor-in-Chief), Dean of the faculty.

- Prof dr. Heba Youssef Mohamed (Deputy- in-chief) vice Dean for postgraduate \& researches.

- Prof. dr. Enas Ebrahim El Sheikh (public health and industrial medicine)

- Prof Dr. Mohamed Abd Elhamid Motawie (Obstetrics and gynecology department)

- Prof Dr. Mamdouh Radwan Elnahas (Internal medicine department)

- Prof Dr.Gamal Eldesoky Soliman (Pediatric and neonatology department)

- Prof. Dr.Ayman Elsaid Galhom (Neurosurgery department)

- Dr. Waleed Elagawy (Editing manager)

- Dr. Carmen Ali Ahmed Ali (management secretary)

- Mr. Ahmed Shabaan Abd Elmalek (Editorial manager) 


\section{Preface}

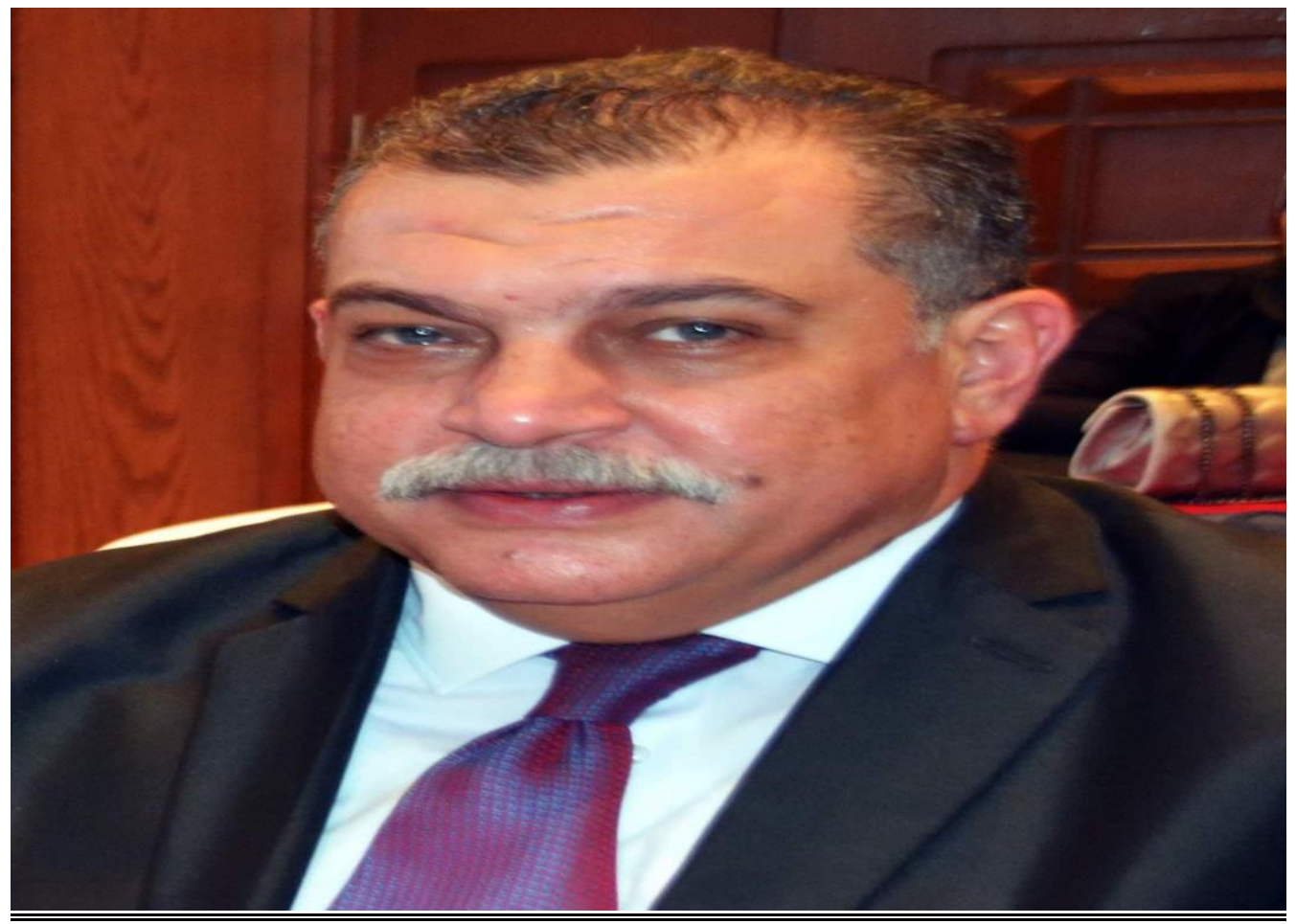

It is my privilege to welcome your Scientific researches in Medicine Updates Journal the official Scientific journal of faculty of Medicine Port said University that is located on line on Egyptian knowledge Bank Professor Dr\Khalid Sabry

\section{Dean of Faculty of Medicine Port said University}

Address: 23 December Street, Port Said, Egypt,_. 


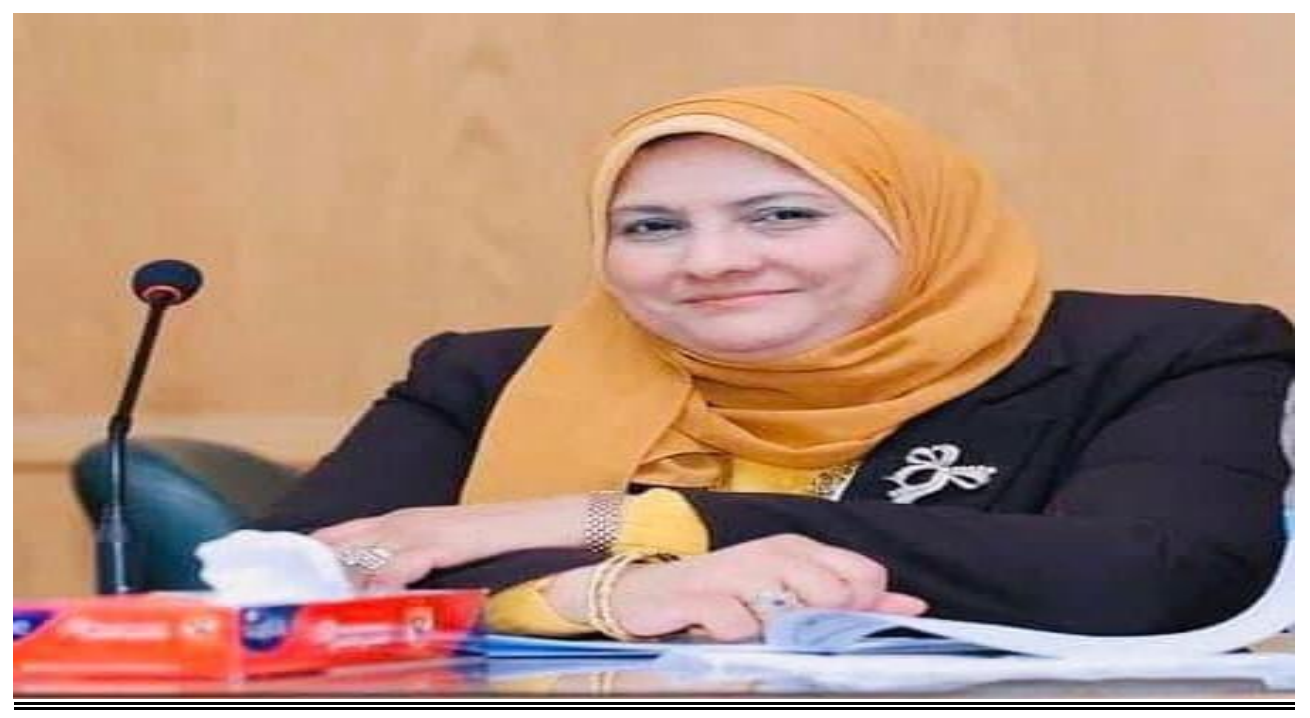

It is great pleasure to welcome all Researchers who are interested in different medical specialties to publish their scientific papers, case studies, patience's ,Master or M.D protocols and conferences Scientific presentations in Faculty of Medicine Port said University online Medicine Updates Journal MUJ present on EKB website

All your scientific work will be reviewed but unique highly expert reviewers and your valuable inputs and feedback will be appreciated

Professor Heba Youssef

Head of clinical Toxicology and Forensic medicine Department

\section{Vice Dean for Postgraduate Affaires}

Address: 23 December Street, Port Said, Egypt, 


\section{Issue Reviewers}

- Medical Pharmacology Department, Port Said University

Associate Prof. Dr. Reham Ibrahim Massoud

- Medical Microbiology \&Immunology Department, Port Said University

Prof. Dr. Refaat Sadek Abd Elsamiaa

- Pediatric And Neonatology Department, Port Said University

Prof. dr. Gamal Taha Soliman

- Internal Medicine Department, Port Said University

Prof. Dr. Mamdouh Radwan Elnahas

- Diagnostic Radiology Department, Helwan University Associate Prof. Dr. Shymaa Abd Elmola Shalaby 


\section{TABLE OF CONTENTS}

No.

The Effect of Amisulpride on Hippocampal Neurogenesis in an Experimental Model of Stressed Rats

Ahmed. Mustafa. Mohamed

The Possible Antidiabetic Effects of Ranolazine Versus

Gliclazide In HFD/STZ-Induced Type 2 Diabetes In Male

Albino Rats

Shereen S. Elkholy

Autologus Serum Therapy Efficacy as Adjunctive Treatment to Antihistaminics in Chronic Spontaneous Urticaria Patients

Heba A.Elsayed

Evaluation of Cardiac Troponin I as a Non Invasive Tool for Diagnosis of the Newborns and Infants Below 6 Months with Congenital Heart Diseases

Mohamed Abd elrahman

Is urinary kim-1 a better biomarker than its serum value in diagnosis of Acute Kidney Injury disease?

Asmaa Mohamed Nabiel Eessa

MRI of male breast carcinoma 
Medicine Updates

Faculty of medicine

April 2020,volume 1, issue 1 https://muj.journals.ekb.eg dean@med.psu.edu.eg vice_dean_postgraduate@med.psu.edu.eg

DOI:10.21608/muj.2020.15734.1000

ISSN : 2682-2741

Submitted: $6 / 8 / 2019$

Accepted : 2/3/2020

Pages:1-8

\section{The Effect of Amisulpride on Hippocampal Neurogenesis in an Experimental Model of Stressed Rats}

Ahmed. Mustafa. Mohamed. Assistant lecturer in pharmacology department of faculty of medicine of port said university

\section{$\underline{\underline{\text { Abstract }}}$}

Rationale: Amisulpride (Sanofi) is atypical antipsychotic against both positive and negative symptoms of schizophrenia . Efficacy is observed against negative symptoms in a low dose range of ( $50-300 \mathrm{mg} /$ day ) while in positive symptoms is observed in a high dose range ( $800-1200 \mathrm{mg} /$ day ) Boyer et al , ( 1994 ). It is a selective and potent antagonist at dopamine D2 and D3 receptors. Also it appears to have a useful potential for treatment of depression Boyer et al ,(1999).

\section{Objectives}

The current study investigated that amisulpride has antidepressant properties over a range of doses in two procedures namely the Forced Swim Test (FST) Porso et al,(1978) and immune-histopathology of Ki67. Also the effect of high versus low dose of amisulpride on hippocampal neurogenesis in male Wistar Han albino rats. 


\section{Methods}

Sixty male albino wistar rats weighing about 150-200 gm are used in three main groups. Group I ( $n=12$ ) were administered vehicle (saline) for 21 days, group II $(n=12)$ exposed to forced swim test (FST) and vehicle (saline)for 21 days, group $I I I(n=36)$ exposed to (FST) and amisulpride. The latter group was divided into three subgroups : IIIA ( $n=12$ ) received $5 \mathrm{mg} / \mathrm{kg} /$ day for 21 days, IIIB ( $n=12$ ) received $10 \mathrm{mg} / \mathrm{kg} /$ day for 21 days, IIIC ( $n=12$ ) received $20 \mathrm{mg} / \mathrm{kg} /$ day for 21days. The rats were observed for behavioural tests as immobility, climbing and swimming times. Then they were anaesthesized using urethane $1 \mathrm{gm} / \mathrm{kg}$ i.p futterer CD, (2004), then decapitated and the brains were quickly removed. Brain samples were placed in $10 \%$ formalin and were processed to form paraffin blocks. Half of them were used for biochemical analysis of BDNF levels in tissue and the other half were prepared and stained with Hematoxylin and eosin ( H\&E )stain and Immunohistochemical staining by Ki 67 (marker for proliferating cells).

\section{Results}

There is an increase of immobility time in seconds in CSS group compared with Control group with Mean \pm SD $(67.00 \pm 8.623$ and $3.333 \pm 1.670$ respectively) with $\mathrm{P}<0.0001$.While treating with oral amisulpride for 21 days in doses of $10 \mathrm{mg} / \mathrm{kg} /$ day and $20 \mathrm{mg} / \mathrm{kg} /$ day result in statistically significant decrease in immobility time as compared with CSS group with $P$ value of $<0.0001$ and $F$ value of $(4,54)=98.67$. Amisulpride in $5 \mathrm{mg} / \mathrm{kg}$ was statistically insignificant.

Also there is a significant decrease in BDNF level in $(\mathrm{pg} / \mathrm{ml})$ in CSS group compared with Control group with Means \pm SD of $(253.6 \pm 45.06$ and463.5 \pm 35.02 respectively ) with $P$ value of $<0.0001$, while treatment with oral Amisulpride in 5,10 and $20 \mathrm{mg} / \mathrm{kg} /$ day result in significantly statistically increase in BDNF value with Means \pm SD $(420.5 \pm 29.84,358.6 \pm 16.72$ and $400.6 \pm 18.18$ respectively)with $P$ values of $<0.0001$ and $F(4,25)=1.276$.

There is a significant statistical decrease in number of Ki-67 positive cells in SVZ in CSS group compared with control group with means (8.000 and 22.30 respectively ) with $P$ value of 0.0101 . Also treatment with oral Amisulpride 5 , $10 \mathrm{mg} / \mathrm{kg} /$ day result in insignificant increase in $\mathrm{Ki}-67$ immunostained cells in 
$\mathrm{SVZ}$, with the maximum statistically increase with $20 \mathrm{mg} / \mathrm{kg} /$ day, with means $(15.78,13.38$ and 28.00 respectively )compared with CSS (Mean 8.000 ) with $P$ values of $0.5108,0.8187$ and 0.0009 respectively and $F(4,40)=6.628$.

\section{Behavioral results:}

Table 1 showing difference in immobility time in seconds among different groups:

\begin{tabular}{|l|l|}
\hline Groups of Rats ( $\mathrm{n}=12$ Rats / group) & $\begin{array}{l}\text { Immobility time in seconds } \\
\text { (Mean } \pm \text { SD })\end{array}$ \\
\hline Control & $3.333 \pm 1.670$ \\
\hline CSS & $67.00 \pm 8.623$ \\
\hline Amisulpride $(5 \mathrm{mg} / \mathrm{kg} /$ day ) & $113.4 \pm 21.09$ \\
\hline Amisulpride $(10 \mathrm{mg} / \mathrm{kg} /$ day ) & $23.58 \pm 14.71$ \\
\hline Amisulpride $(20 \mathrm{mg} / \mathrm{kg} /$ day ) & $20.09 \pm 22.18$ \\
\hline
\end{tabular}

Results are presented as Mean \pm SD ( $n=12$ animals / group ).

Fig 1 by using Graphpad prism :

\section{Immobility time}

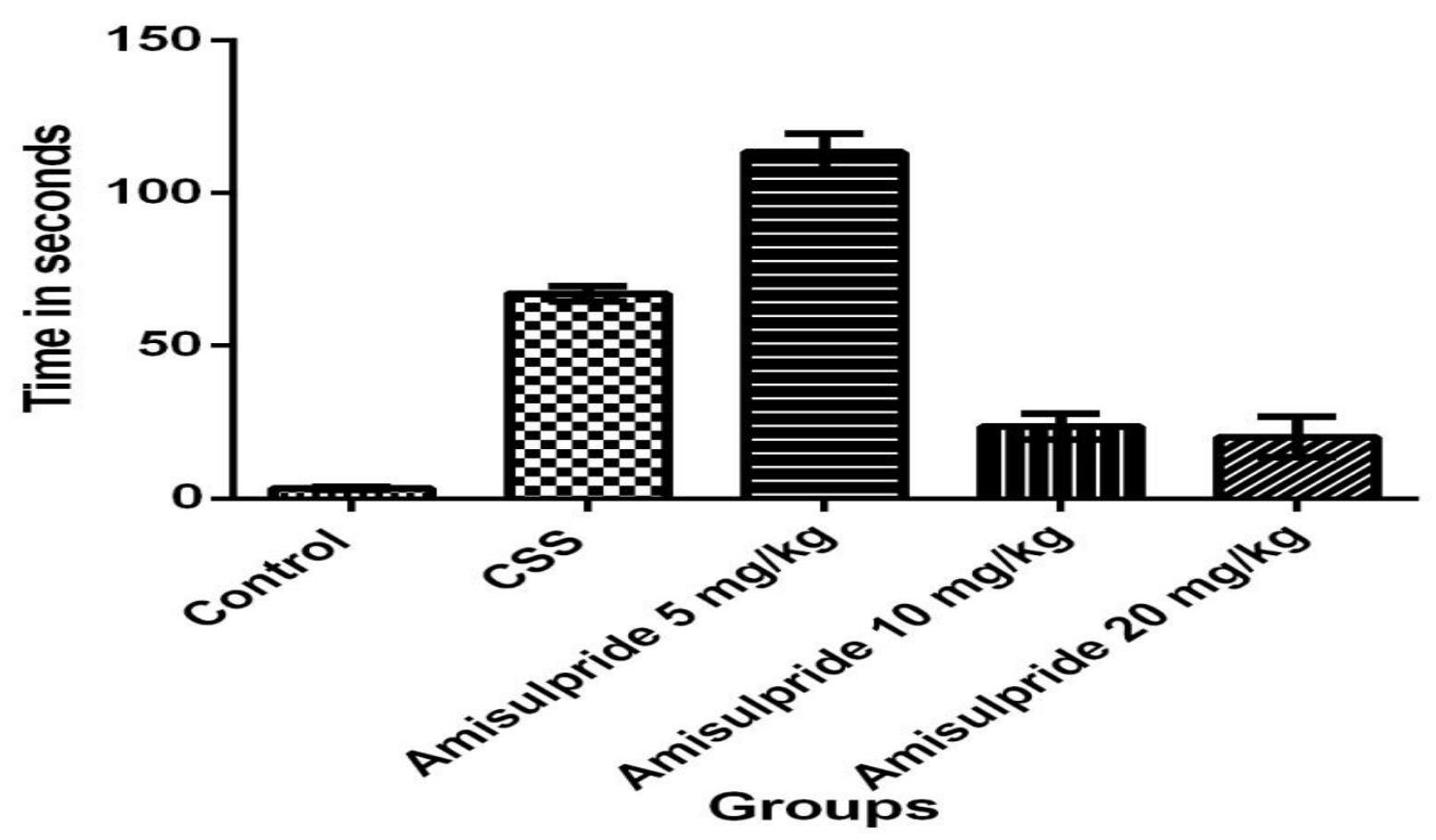




\section{Biochemical results:}

Table 2 showing difference in BDNF levels in (pg/ml)among groups:

\begin{tabular}{|l|l|}
\hline Groups of Rats $(\mathrm{n}=12$ Rats/group) & BDNF in $(\mathrm{ng} / \mathrm{ml})$ as Mean $\pm S D$ \\
\hline Control & $463.5 \pm 35.02$ \\
\hline CSS & $253.6 \pm 45.06$ \\
\hline Amisulpride $(5 \mathrm{mg} / \mathrm{kg} /$ day) & $420.5 \pm 29.84$ \\
\hline Amisulpride $(10 \mathrm{mg} / \mathrm{kg} /$ day) & $358.6 \pm 16.72$ \\
\hline Amisulpride $(20 \mathrm{mg} / \mathrm{kg} /$ day) & $400.6 \pm 18.18$ \\
\hline
\end{tabular}

Results are presented as Mean \pm SD ( $n=12$ animals/group).

Fig 2: BDNF level

\section{BDNF ELISA}

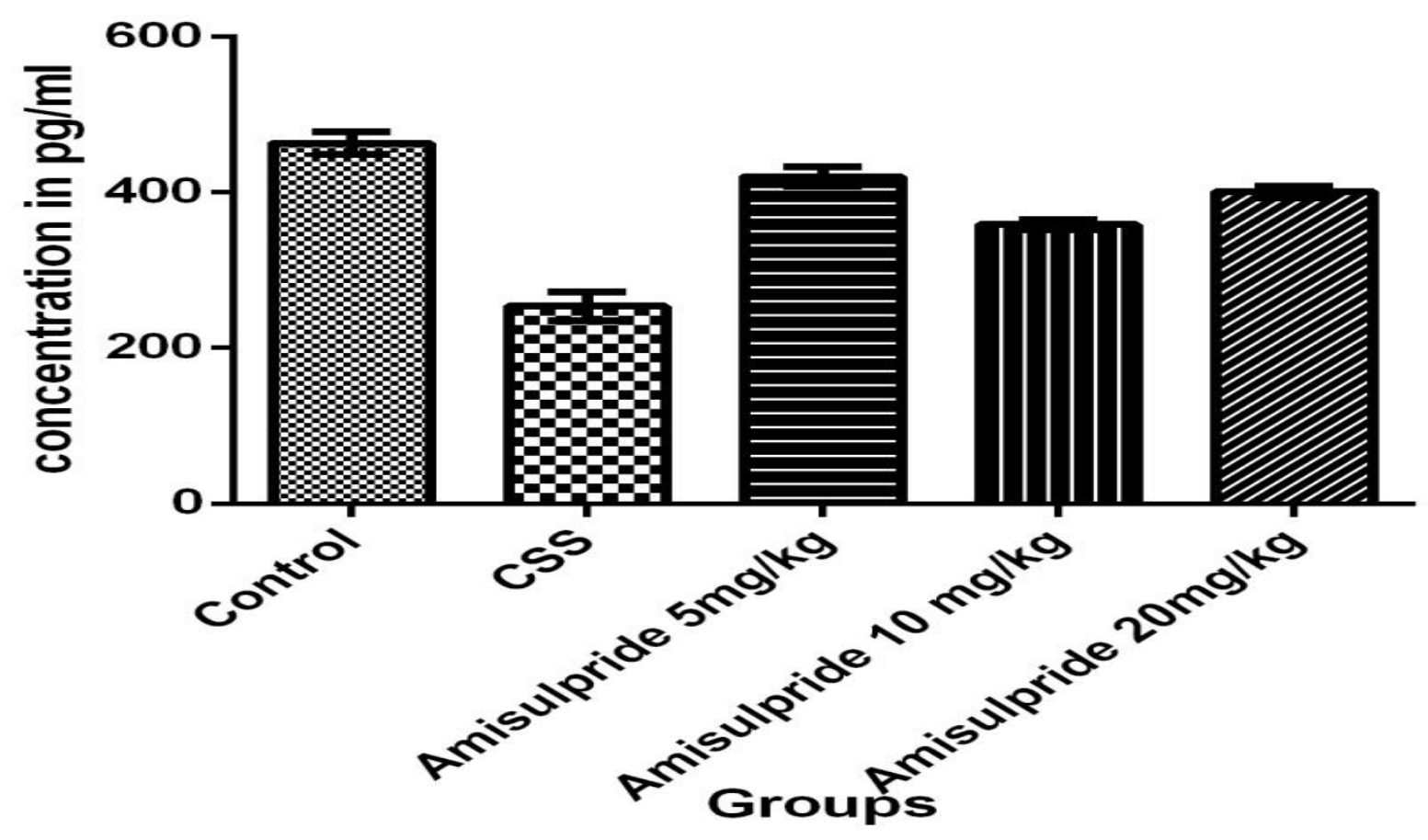




\section{Histological results:}

Table 3 showing number of Ki-67 immunostained cells/HPF in SVZ

\begin{tabular}{|l|l|}
\hline Groups of Rats ( $\mathrm{n}=12$ Rats/group) & $\begin{array}{l}\text { Number of Ki-67 positive cells } \\
\text { in SVZ }(\text { Mean } \pm \text { SD) }\end{array}$ \\
\hline Control & $22.30 \pm 5.229$ \\
\hline CSS & $8.000 \pm 2.966$ \\
\hline Amisulpride $(5 \mathrm{mg} / \mathrm{kg} /$ day) & $15.78 \pm 8.136$ \\
\hline Amisulpride $(10 \mathrm{mg} / \mathrm{kg} /$ day) & $13.38 \pm 5.630$ \\
\hline Amisulpride $(20 \mathrm{mg} / \mathrm{kg} /$ day) & $28.00 \pm 14.75$ \\
\hline
\end{tabular}

Results are presented as Mean $\pm S D, n=12$ animals /group.

Fig 3 Number of Ki-67 immunostained cells/HPF in SVZ.

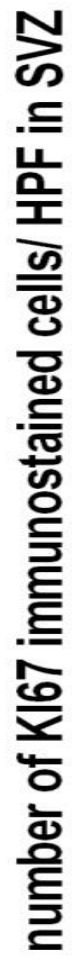

Ki67 positive cells in SVZ

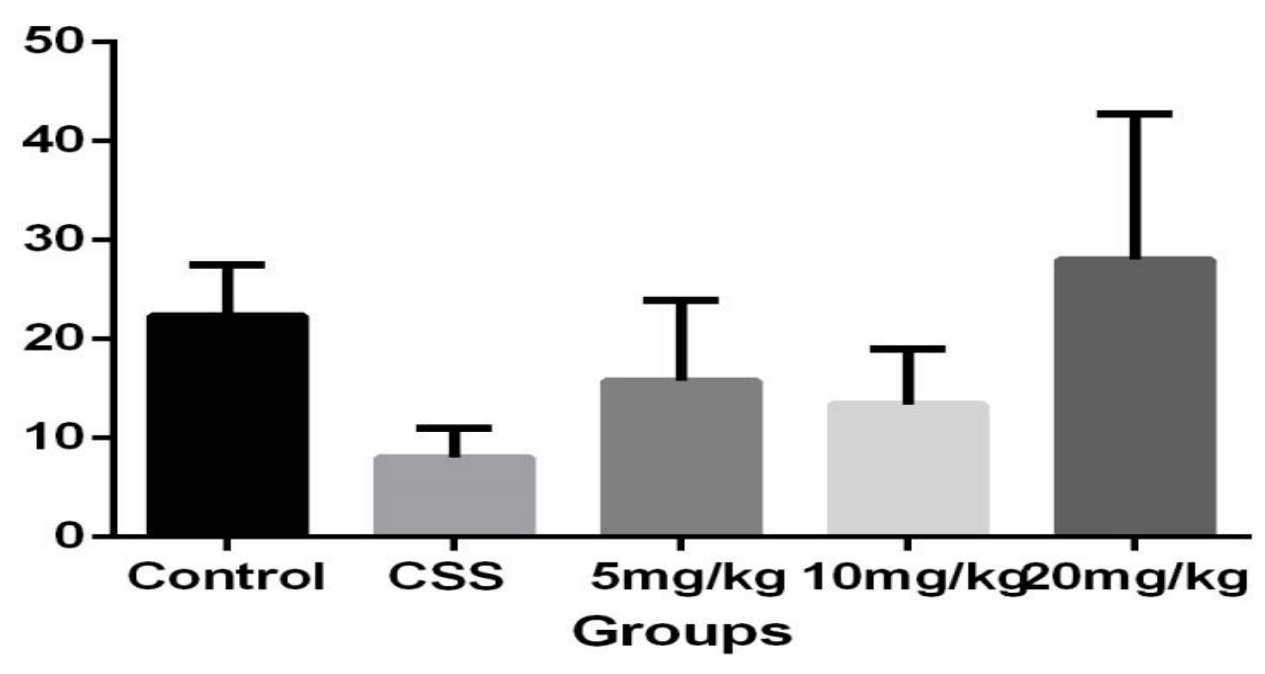






Fig 3 A: Micrograph showing immunohistochemistry of Ki-67 in SVZ ( $\uparrow)$ in the control group (100x, for inset 400x).

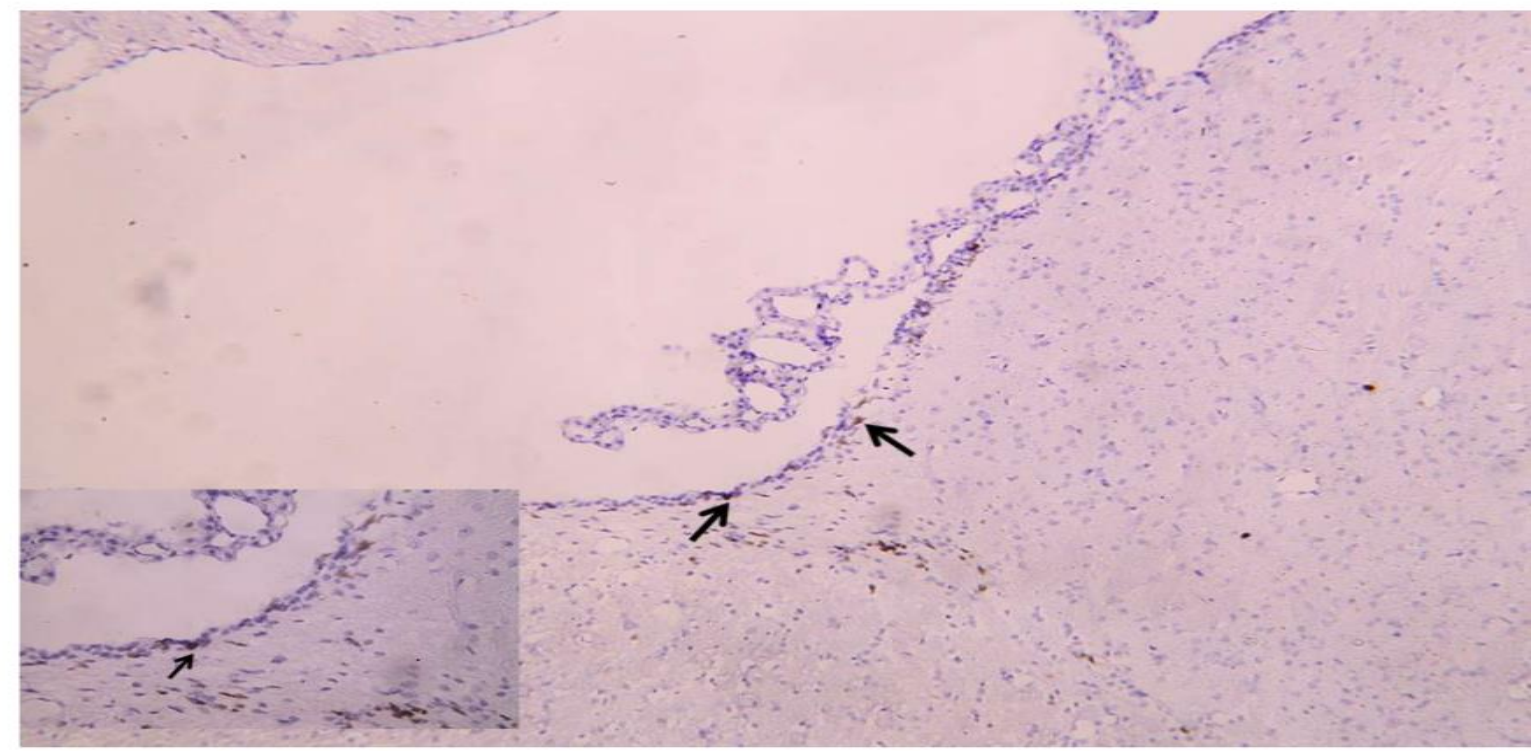

Fig 3 B : Micrograph showing immunohistochemistry of Ki-67 in SVZ ( $\uparrow$ ) in CSS group. A decrease in the number of Ki-67 positive cells is seen (100x, for inset 400x). 


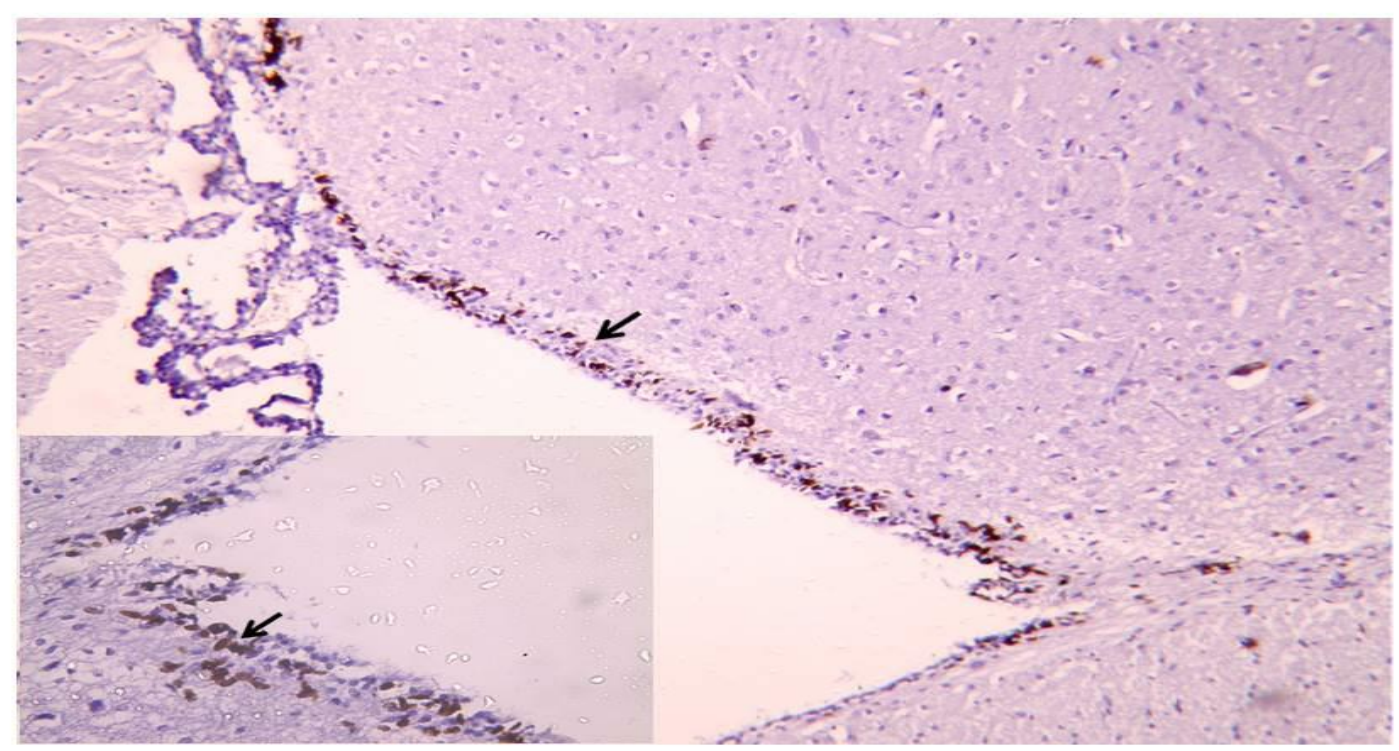

Fig $3 \mathrm{E}$ : Micrograph showing immunohistochemistry of Ki-67 in SVZ ( $\uparrow$ ) in amisulpride $20 \mathrm{mg}$ treated group. An apparent increase in $\mathrm{Ki}-67$ positive cells is seen $(100 x$, for inset 400x).

\section{Conclusion:}

Amisulpride showed antidepressant effect over a ranger of doses as in 10 \& $20 \mathrm{mg} / \mathrm{kg} /$ day in addition to its antipsychotic effects. Moreover, the hippocampal neurogenesis may be altered in immunepsychiateric disorders like depression and neurodegenerative disorders.

\section{References:}

1- Benavides J, Boyer, Carter C, Chergui K, Cudennec A, Fage D, Gonon F, Perrault G, Sanger D J, Scatton B, Shoemaker H, Sramek (1994): Pharmacological profile of amisulpride, an atypical neuroleptic which preferentially blocks presynaptic D2/D3 receptors. Neuropsychopharmacology 10 (Suppl. 1): 242S.

2- Briones TL, Futterer CD, Suh E, Jozsa L, Hattar H, Chai J, Wadowska $M$ (2004). "Behaviorally-induced ultrastructural plasticity in the hippocampal region after cerebral ischemia". Brain Research. 997 (2): 137-46. 
3- Can, A.; et, al (2012). "The Mouse Forced Swim Test". Journal of Visualized Experiments. 59 (3638).

4- Cattaneo A, Cattane N, Begni V, Pariante CM, Riva MA (2016). The human BDNF gene: peripheral gene expression and protein levels as biomarkers for psychiatric disorders. Transl Psychiatry. 6(11):e958.

5- Porsolt, R.D., Bertin, A. \& Jalfre, M (1978). 'Behavioural despair' in rats and mice: strain differences and the effects of imipramine. Eur. J. Pharmacol. 51, 291-294.

6- Porsolt, RD; Le Pichon, M; Jalfre, M (1977). "Depression: a new animal model sensitive to antidepressant treatments.". Nature. 266 (5604): 7302.

7- Raju TR, , Srikumar BN, Veena J (2009) :Exposure to enriched environment restores the survival and differentiation of new born cells in the hippocampus and ameliorates depressive symptoms in chronically stressed rats. Neurosci Lett ;455: 178-182. 
Medicine Updates

Faculty of medicine

April 2020,volume 1, issue 1 https://muj.journals.ekb.eg dean@med.psu.edu.eg vice_dean_postgraduate@med.psu.edu.eg

DOI:10.21608/muj.2020.25106.1007

ISSN : 2682-2741

Submitted: $3 / 3 / 2020$

Accepted : 4/3/2020

Pages:9-28

\section{The Possible Antidiabetic Effects of Ranolazine Versus Gliclazide In HFD/STZ-Induced Type 2 Diabetes In Male Albino Rats}

Shereen S. Elkholy, Department of Pharmacology, Faculty of Medicine, Portsaid University, Portsaid

\section{Abstract}

Background: Type 2 diabetes is a major illness that affects millions of people. The key causes of type 2 diabetes are insulin resistance and decreased insulin secretion

Objectives: To evaluate the possible effects of ranolazine versus gliclazide on blood glucose levels, $\mathrm{HbA} 1 \mathrm{c}$, nitric oxide and oxidative stress markers in HFD/STZ-induced type 2 diabetes in male albino rats and their effect on the histopathological picture of the pancreas and on apoptosis .

Materials and Methods: Thirty-two male albino rats were divided into four groups. The normal control group which received saline ( $1 \mathrm{mg} / \mathrm{kg} /$ day) for 5 weeks. The diabetic control group that received saline $(1 \mathrm{mg} / \mathrm{kg} / \mathrm{day})$ for 5 weeks. The gliclazide-treated group that received gliclazide $(10 \mathrm{mg} / \mathrm{kg}$ ) twice daily for 5 weeks and the ranolazine-treated group that received ranolazine (20 $\mathrm{mg} / \mathrm{kg}$ ) twice daily for 5 weeks. Body weight and blood glucose levels were measured weekly for the 5 weeks, then blood samples were obtained for various biochemical analysis: lipid profile, $\mathrm{HbA1C}, \mathrm{AGEs}$ and NO. Then rats were sacrificed and the pancreatic tissues were obtained for oxidative stress markers 
estimation, for histopathological examination using haematoxylin and eosin stain and for estimation of caspase-3 marker.

Results: Ranolazine improved diabetes by reducing fasting blood glucose level, $\mathrm{HbA1c}$, NO and AGEs. Moreover, it improved the oxidative stress markers, the histopathological picture of the pancreas and decreased the apoptosis.

Conclusion: Ranolazine has the potential to become a novel agent for treating type 2 diabetes patients .

Keywords: Diabetes mellitus, STZ, Oxidative stress markers, Caspase-3, HbA1c.

\section{$\underline{\underline{\text { Introduction }}}$}

Type 2 diabetes is a major illness that affects millions of people. The chief causes of type 2 diabetes are insulin resistance and decreased insulin secretion[1]. About 2,623,000 people in Egypt are affected, with the expectation of 6,726,000 people in 2030 [2]. Moreover, Type 2 diabetes is considered a risk factor for cardiovascular events and is a substantial predictor of cardiovascular morbidity and mortality [3].

Ranolazine is a novel drug for angina that decreases frequency of angina attacks and recovers exercise tolerance in the affected patients [4]. Ranolazine is a selective inhibitor of cardiac late sodium channels that result in decreasing the intracellular $\mathrm{Na}^{+}$and $\mathrm{Ca}^{+2}$, leading to its anti-anginal properties in myocardial ischemia. [5]. Ranolazine also has been revealed to lower $\mathrm{HbA}_{1 \mathrm{c}}$ in cardiac patients with comorbid diabetes [6]. In the Combination Assessment of Ranolazine In Stable Angina trial, ranolazine significantly lowered HbA1c levels by $0.7 \pm 0.18 \%$ when it is given for 12 weeks irrespective of concomitant oral antidiabetic therapy. Furthermore, long-term ranolazine treatment shows preservation of $\beta$-cell and improvement of insulin secretion [7]. 
Gliclazide is a standard drug that used frequently for type 2 diabetes mellitus (DM) treatment. The drug stimulates the pancreatic $\beta$-cells to release insulin resulting in reduction of blood glucose level. Moreover, gliclazide has antioxidant and extra - pancreatic properties [8].

Linking the fact that calcium channel antagonists and $\beta$-receptor blockers produce hyperglycmia and that ranolazine behaves as an add on treatment for beta-antagonists and calcium channel antagonists in anginal patients with the fact that ranolazine has been revealed to lower $\mathrm{HbA}_{1 c}$ in patients with angina, ranolazine was logical applicant for study. Therefore, the current study was conducted to observe the possible antidiabetic effect of ranolazine and its mechanisms in HFD/STZ- induced type 2 diabetes in rats.

\section{Materials and Methods}

Experimental animals: Thirty-two adult male albino rats, weighing 180-200 g. They were accommodated in polyethylene cages with free access to to standard animal diet or HFD and tap water ad libitum. The rats were kept under standard conditions of normal light-dark cycle and temperature adjusted between $25-30^{\circ} \mathrm{C}$.

Induction of type-2 diabetes: Rats were fed with a high fat diet (HFD) for four weeks. Followed by receiving a single injection of STZ (30 mg/kg, i.p.) [9]. Three days after STZ injection, rats with fasting blood glucose levels $>200 \mathrm{mg} / \mathrm{dl}$ were designated as diabetic [10]. Then, rats divided into four groups of eight animals each. The normal control group that received saline $(1 \mathrm{mg} / \mathrm{kg} /$ day) for 5 weeks. The diabetic control group that received saline $(1 \mathrm{mg} / \mathrm{kg} / \mathrm{day})$ for 5 weeks. The gliclazide-treated group that received oral gliclazide $(10 \mathrm{mg} / \mathrm{kg}$ ) twice daily for 5 weeks [11]. The ranolazine-treated group that received oral ranolazine $(20 \mathrm{mg} / \mathrm{kg})$ twice daily for 5 weeks [12]. 
Body weights and blood glucose levels were measured weekly for the 5 weeks. Insulin resistance was assessed using the homeostasis model assessment for insulin resistance (HOMA-IR) index. At the end of 5 weeks treatment, blood samples were obtained for various biochemical analysis: HbA1c, Lipid profile (Total cholesterol, HDL, TG, LDL and VLDL), advanced glycated endproducts (AGEs) and nitric oxide (NO). Then rats were sacrificed and The pancreatic tissues were gained for oxidative stress markers (MDA, SOD, GSH, CAT) estimation, for histopathological examination using hematoxylin and eosin (H and $\mathrm{E}$ ) stain and for caspase-3 marker assessment by immunohistochemical staining. Assessment of caspase 3 staining using semiquantitative method: The $\mathrm{H}$ score. An $\mathrm{H}$-score was attained between 0 and 300 where 300 was equivalent to $100 \%$ of islets cells of pancreas stained strongly $(3+)$ [13].

Statistical analysis: All the grouped data were statistically estimated using statistical package for social sciences (SPSS) program (windows version number 10) and were expressed as mean \pm SEM. The gained data were analyzed by one-way ANOVA followed by Banferroni's multiple comparisons test. Data with a $\mathrm{P}$ value $<0.05$ were considered statistically significant.

\section{$\underline{\underline{\text { Results }}}$}

Fig (1) Revealed that HFD/STZ-challenged rats showed significant surge in FBS levels in comparison to the normal control group $(\mathrm{p}<0.05)$ beginning from the start of the study and continued till the end of experiment. Treatment with either gliclizide or ranolazine significantly $(\mathrm{p}<0.05)$ lowered FBS levels as compared to diabetic control group; with significant $(\mathrm{p}<0.05)$ differences between the two treated groups.

Fig (2) and Table (1) Revealed that HFD/STZ-challenged rats showed significant reduction in BW in comparison with normal control group $(\mathrm{p}<0.05)$ starting from the fourth week. Treatment with gliclizide significantly $(\mathrm{p}<0.05)$ elevate BW as compared to diabetic control group starting from the third week. 
Treatment with ranolazine significantly $(\mathrm{p}<0.05)$ rise $\mathrm{BW}$ as compared to diabetic control group starting from the second week; with significant $(\mathrm{p}<0.05)$ differences between the two treated groups.

Table (2) Revealed that HFD/STZ-challenged rats showed a significant augmentation in cholesterol, LDL, TG, and VLDL levels accompanying by significant reduction in HDL levels compared to normal-control group $(\mathrm{p}<0.05)$. Treatment with either gliclizide or ranolazine significantly mitigated these parameters as compared to diabetic-control group $(\mathrm{p}<0.05)$ with significant $(\mathrm{p}<0.05)$ differences between the two treated groups in LDL only.

Fig (3) Showed that HFD/STZ-challenged rats was associated with significant $(\mathrm{p}<0.05)$ surge in $\mathrm{HbA}_{1 \mathrm{c}}$, HOMA, AGEs, and $\mathrm{NO}$ levels in comparison with the normal control group. Treatment with either gliclizide or ranolazine significantly $(\mathrm{p}<0.05)$ ameliorated these augmented levels compared to diabetic control group with insignificant $(p>0.05)$ differences between the two treated groups except on HOMA and NO level where treatment with ranolazine significantly $(\mathrm{p}<0.05)$ decreased HOMA and NO level in comparison with gliclizide treated group.

Fig (4) Showed that HFD/STZ-challenged rats increased oxidative stress in the form of significant $(\mathrm{p}<0.05)$ augmentation of MDA level and significant $(\mathrm{p}<0.05)$ decrease in GSH, SOD and CAT levels compared to normal control group. These lethal effects were significantly $(\mathrm{p}<0.05)$ improved with either gliclizide or ranolazine as compared to diabetic control group with insignificant $(p>0.05)$ differences between the two treated groups on MDA level. Clearly, treatment with ranolazine revealed significant difference $(p<0.05)$ in GSH, SOD and CAT levels compared to gliclizide treated group.

Fig (5A-D) Examination of $\mathrm{H}$ and $\mathrm{E}$ stained islets of pancreas exhibited that: In normal-control group, there was preserved rounded contour of islets (C), the cells have eosinophilic cytoplasm, some are arranged in acinar pattern (Fig-5A). On the other hand, pancreatic islets cells from diabetic-control group 
showed lost rounded contour of islets with islets shrinkage due to reduction in the number of cells within each islet. The cells have eosinophilic cytoplasm, rounded to angulated nuclei and lost acinar pattern with shrunken cells size. Most of cells showed vacuolar (hydropic) degeneration (V), with scattered deeply stained eosinophilic bodies (apoptotic bodies) (A) (Fig-5B). Treatment with gliclizide showed focally restored contour of some islets, others still have irregular contours and less cellular due to an increase in the number of cells within each islet. The cells have eosinophilic cytoplasm, rounded to angulated nuclei, still lost acinar pattern and residual vacuolar (hydropic) degeneration, with apoptotic bodies (Fig-5C). Treatment with ranolazine showed restored rounded contour of islets; having cellular islets due to an increase in the number of cells within each islet. The cells have eosinophilic cytoplasm, rounded regular nuclei, restored acinar pattern, no vacuolar (hydropic) degeneration, with very few apoptotic bodies (Fig-5D).

Fig 6(I,II) Revealed that in normal-control group, pancreatic islets cells showed no staining, or very weak staining (Fig 6-IA). On the other hand, pancreatic islets cells from diabetic-control group showed moderate to marked staining (Fig 6-IB) with significant $(\mathrm{p}<0.05)$ augmentation of caspase-3 level in comparison with the normal control group (Fig 6-II). Treatment with either gliclizide or ranolazine showed decreased staining(Fig 6-IC,ID) with significant $(\mathrm{p}<0.05)$ decrease in caspase-3 level in comparison with diabetic control group (Fig 6-II). Treatment with ranolazine significantly $(\mathrm{p}<0.05)$ reduced caspase-3 level compared to gliclizide treated group(Fig 6-II).

Figure 1: Effect of Gliclizide and Ranolazine on FBG (mg/dl) levels in HFD and low dose STZ-induced diabetic rats: 


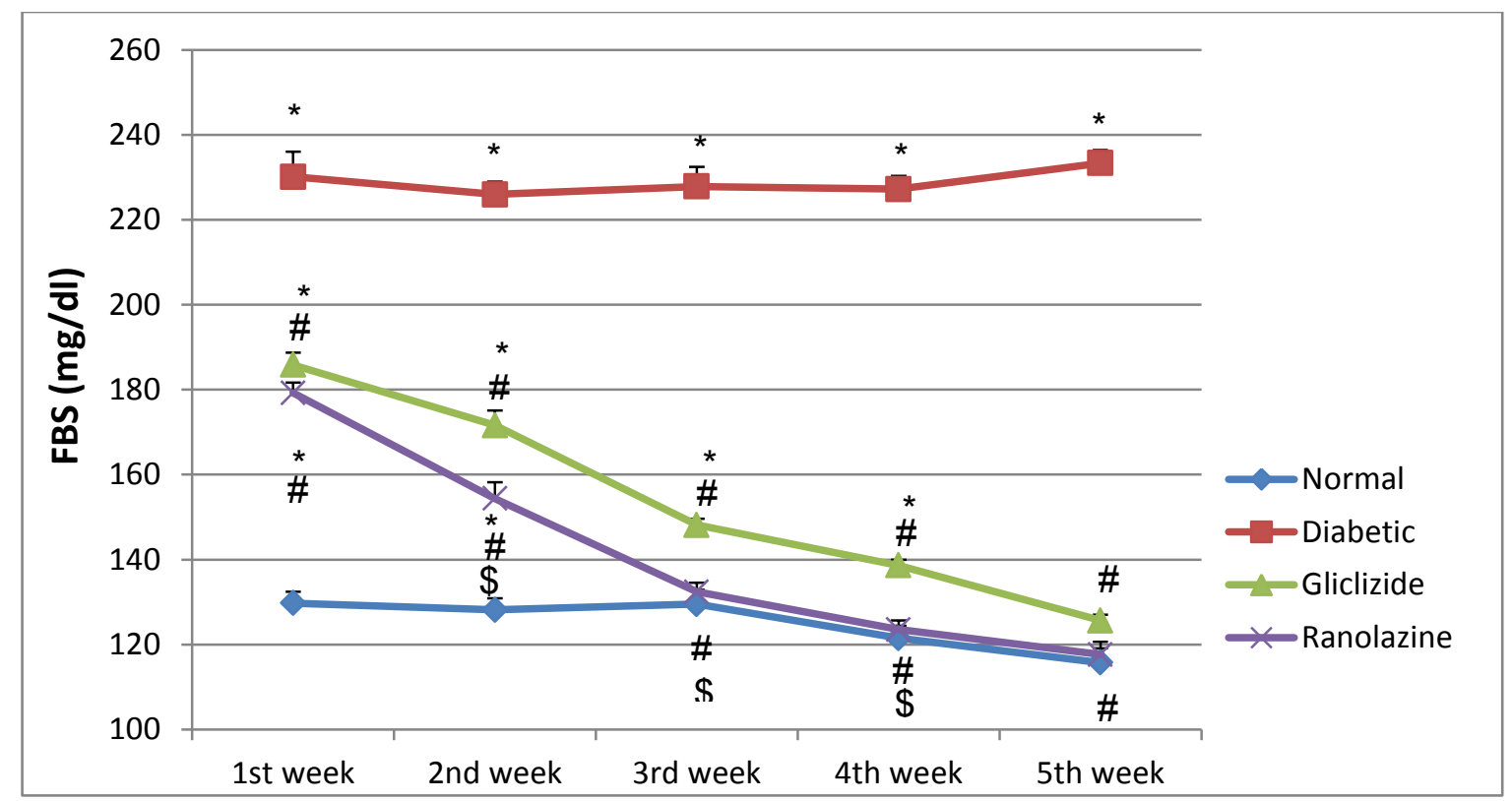

*Statistically significant difference versus normal control group (P-value $<0.05)$ \# Statistically significant difference versus diabetic control group (P-value $<0.05)$ $\$$ Statistically significant difference versus gliclazide-treated group $(P$-value $<0.05)$

Figure 2: Effect of Gliclizide and Ranolazine on body weight (BW) (grams) in HFD and low dose STZ-induced diabetic rats:

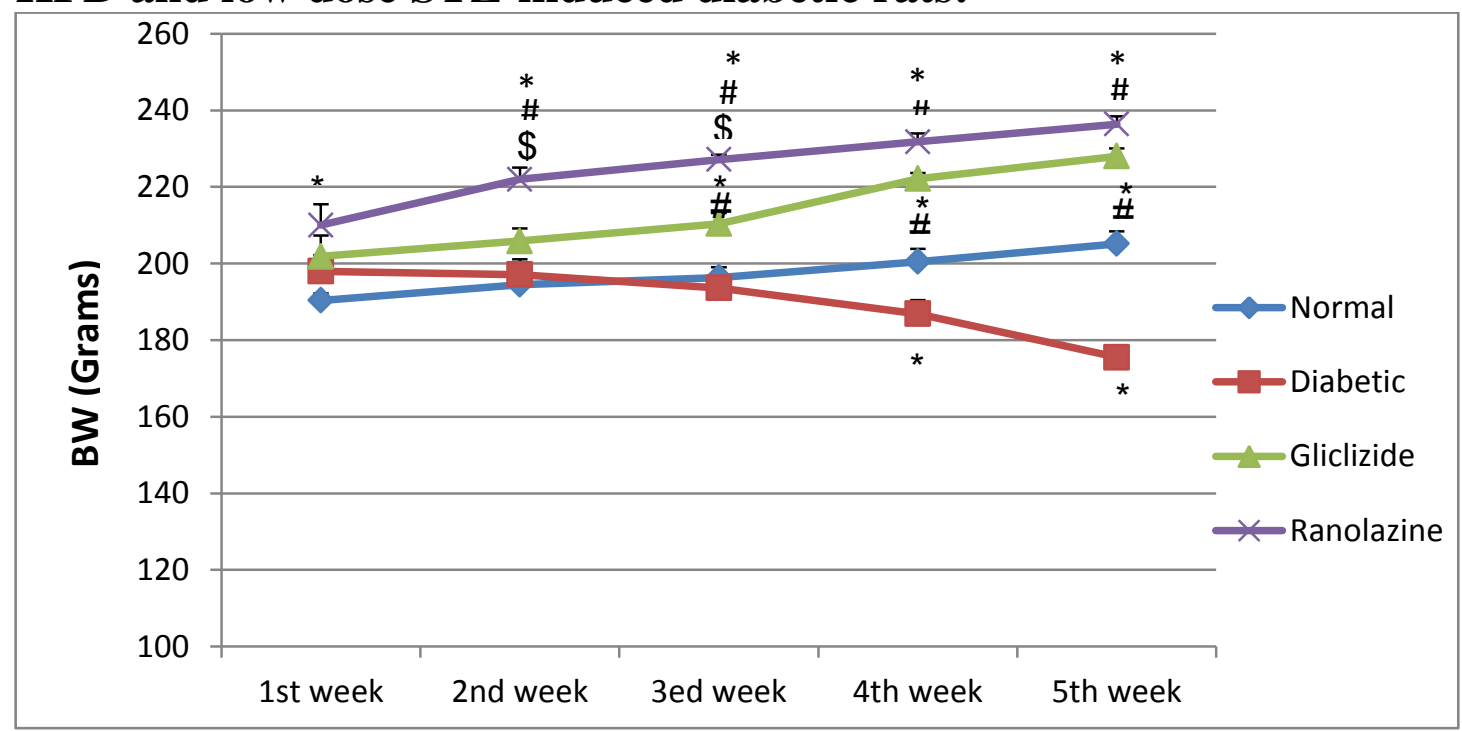

*Statistically significant difference versus normal control group $(P$-value $<0.05)$ \# Statistically significant difference versus diabetic control group (P-value $<0.05)$ $\$$ Statistically significant difference versus gliclazide-treated group $(P$-value $<0.05)$ 
Table 1: Body weight of all experimental groups at the end of the study:

\begin{tabular}{|l|c|}
\hline & $\begin{array}{c}\text { Body weight }(\mathrm{g}) \\
\text { (Mean } \pm \text { SEM) }\end{array}$ \\
\hline Normal control & $205 \pm 3.3$ \\
\hline Diabetic control & $176 \pm 2^{*}$ \\
\hline Gliclizide & $228 \pm 2.1^{* \#}$ \\
\hline Ranolazine & $236 \pm 2.1^{* \#}$ \\
\hline
\end{tabular}

*Statistically significant difference versus normal control group $(P$-value $<0.05)$

\# Statistically significant difference versus diabetic control group $(P$-value $<0.05)$

$\$$ Statistically significant difference versus gliclazide-treated group $(P$-value $<0.05)$

Table 2: Comparison of lipid profile (cholesterol (mg/dl), TG (mg/dl), HDL (mg/dl), LDL (mg/dl) and VLDL(mg/dl)) among the experimental groups.

\begin{tabular}{|c|c|c|c|c|c|}
\hline & $\begin{array}{c}\text { Cholesterol } \\
(\mathrm{mg} / \mathrm{dl})\end{array}$ & $\begin{array}{c}\text { TG } \\
(\mathrm{mg} / \mathrm{dl})\end{array}$ & $\begin{array}{c}\text { HDL } \\
(\mathrm{mg} / \mathrm{dl})\end{array}$ & $\begin{array}{c}\text { LDL } \\
(\mathrm{mg} / \mathrm{dl})\end{array}$ & $\begin{array}{c}\text { VLDL } \\
(\mathrm{mg} / \mathrm{dl})\end{array}$ \\
\hline Normal & $93 \pm 5$ & $60 \pm 4$ & $49 \pm 3.7$ & $33 \pm 3.8$ & $28 \pm 1.3$ \\
\hline Diabetic control & $224 \pm 8^{*}$ & $159.5 \pm 0.5^{*}$ & $31 \pm 1.4^{*}$ & $149 \pm 4.8^{*}$ & $66 \pm 4.4^{*}$ \\
\hline Gliclizide & $119 \pm 12^{\#}$ & $78 \pm 5.5^{* \#}$ & $46 \pm 1.9^{\#}$ & $61 \pm 10.9^{* \#}$ & $34 \pm 2.5^{\#}$ \\
\hline Ranolazine & $94 \pm 5.5^{\#}$ & $68 \pm 4.3^{\#}$ & $49 \pm 1^{\#}$ & $38 \pm 3.5^{\# \$}$ & $31 \pm 1.7^{\#}$ \\
\hline
\end{tabular}

*Statistically significant difference versus normal control group $(P$-value $<0.05)$ \# Statistically significant difference versus diabetic control group $(P$-value $<0.05)$

$\$$ Statistically significant difference versus gliclazide-treated group $(P$-value $<0.05)$ 
Figure 3: Effect of Gliclizide and Ranolazine on $\mathrm{HbA}_{1 \mathrm{c}}(\operatorname{serum} \%)$, AGEs (Mmol/l), HOMA (HOMA-RI Index) and NO (nmol/ml) in HFD and low dose STZ-induced diabetic rats:
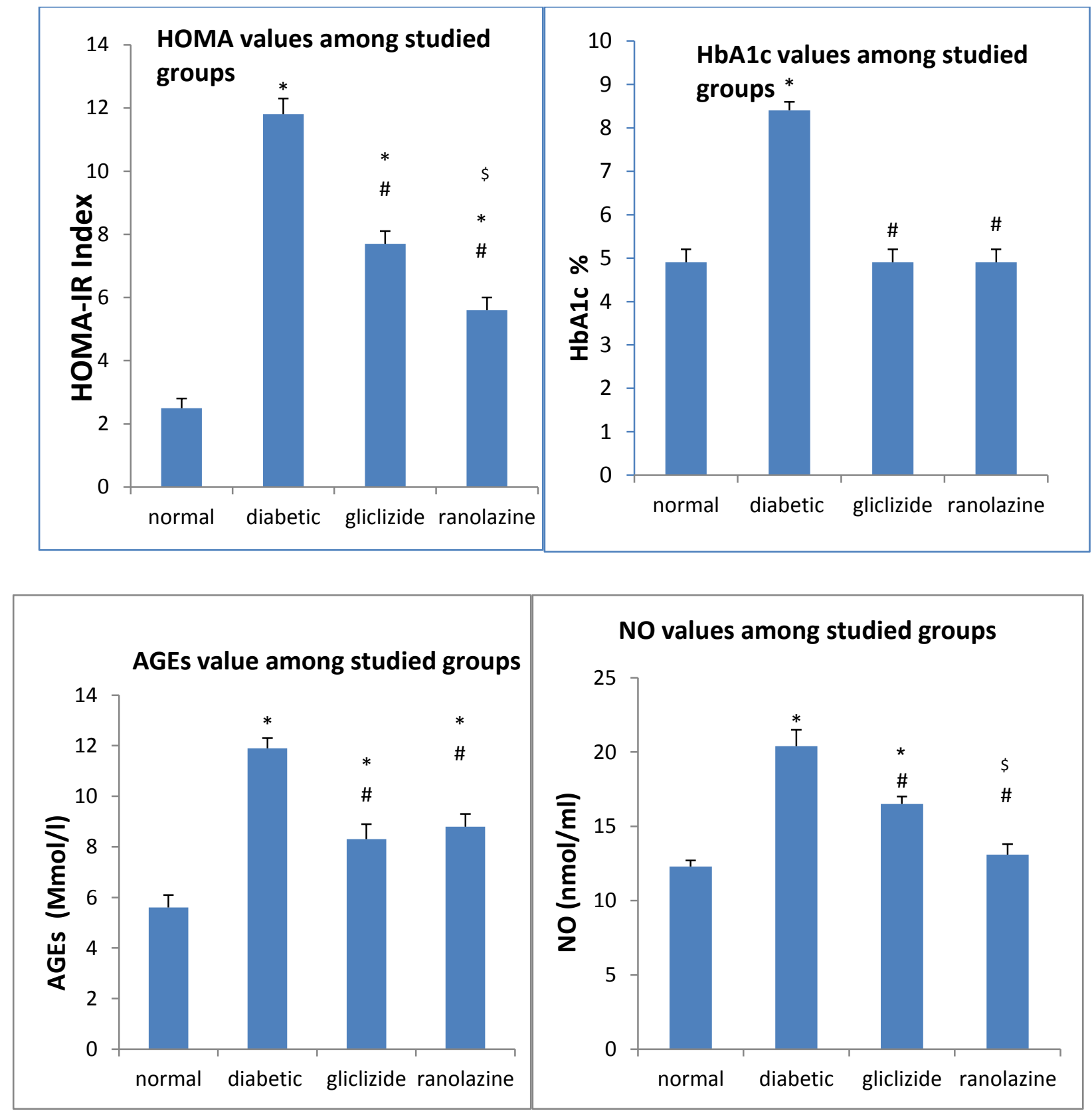

*Statistically significant difference versus normal control group (P-value $<0.05)$ \# Statistically significant difference versus diabetic control group $(P$-value $<0.05)$ $\$$ Statistically significant difference versus gliclazide-treated group $(P$-value $<0.05)$ 
Figure 4: Effect of Gliclizide and Ranolazine on oxidative stress markers (MDA (nmol/g), GSH (mg/g), SOD (U/g) and CAT (U/g)) in HFD and low dose STZ-induced diabetic rats:
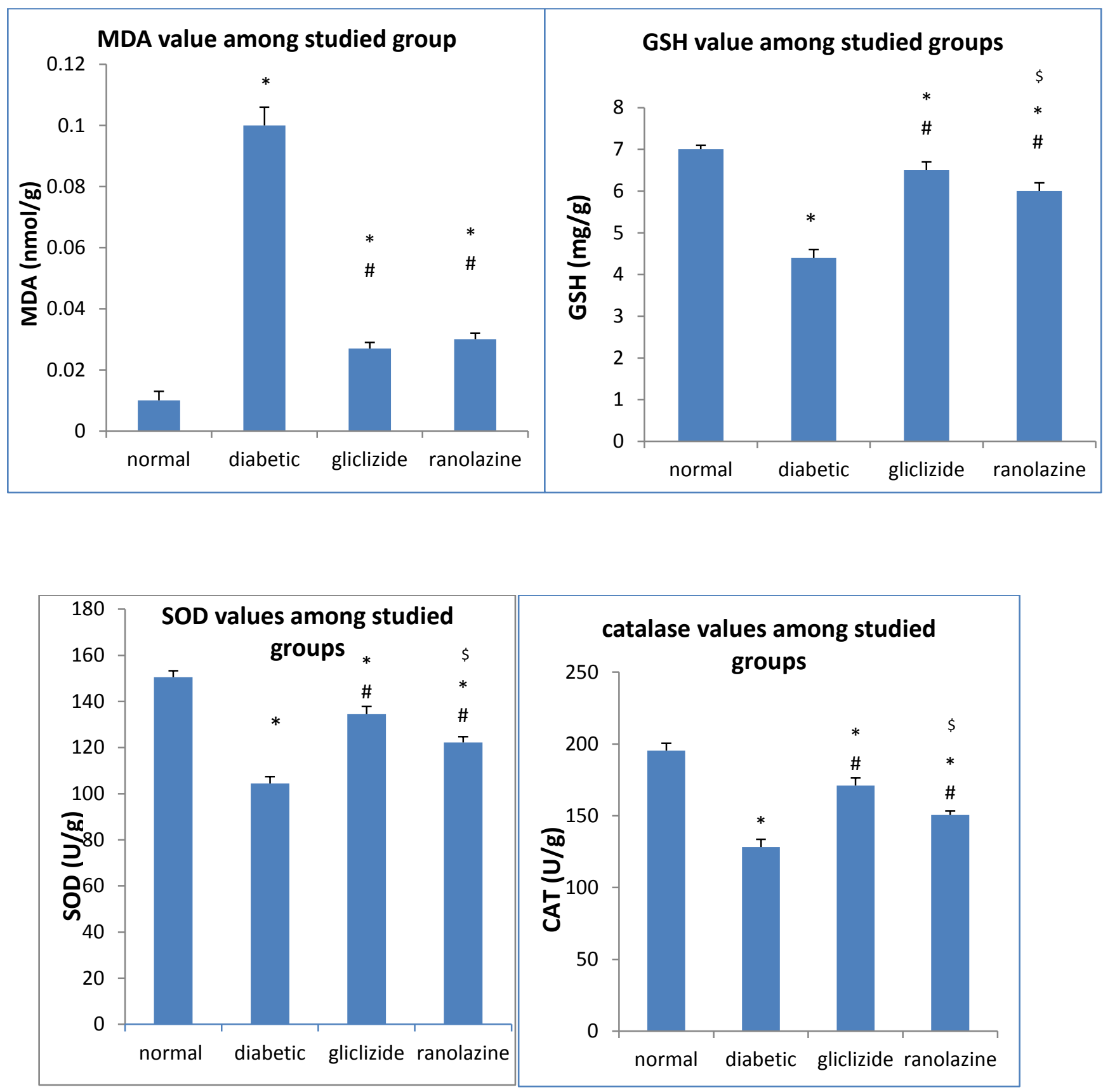

*Statistically significant difference versus normal control group (P-value $<0.05)$ \# Statistically significant difference versus diabetic control group $(P$-value $<0.05)$ $\$$ Statistically significant difference versus gliclazide-treated group $(P$-value $<0.05)$ 
Figure 5: Histopathological evaluation of pancreatic islets stained with H/E.
(A) Normal control group
(B)Diabetic control group (C)Gliclazide treated group
(D)Ranolazine treated group

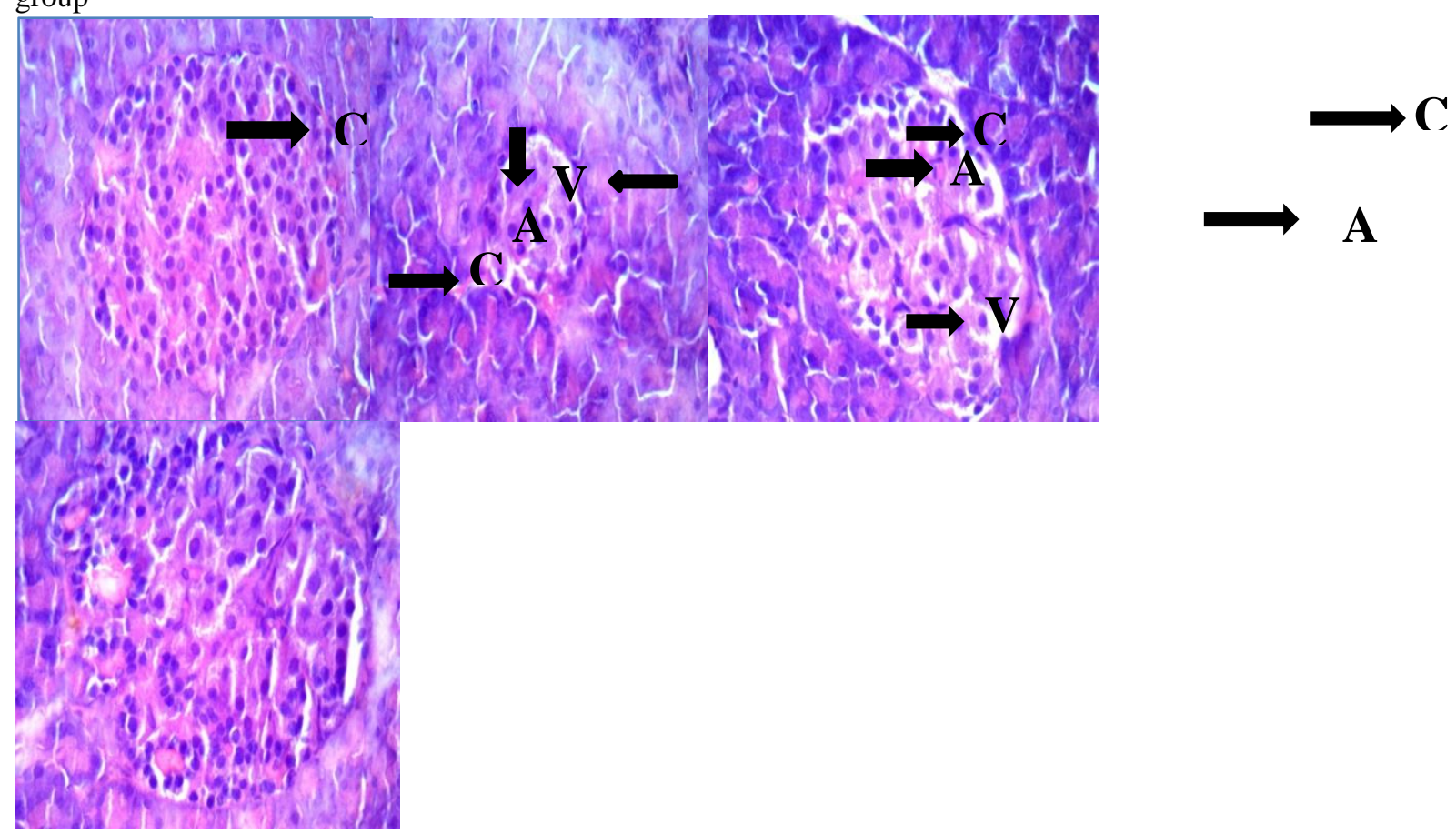

Fig. (5A-D) A photomicrograph of a section in pancreatic islets of a rat from all experimental groups (H\&EX400).

\section{Figure 6: Immunohistochemical staining of pancreatic islets for estimation of caspase-3.}

6(I)(A)Normal control group (B)Diabetic control group (C)Gliclazide treated group (D)Ranolazine treated group

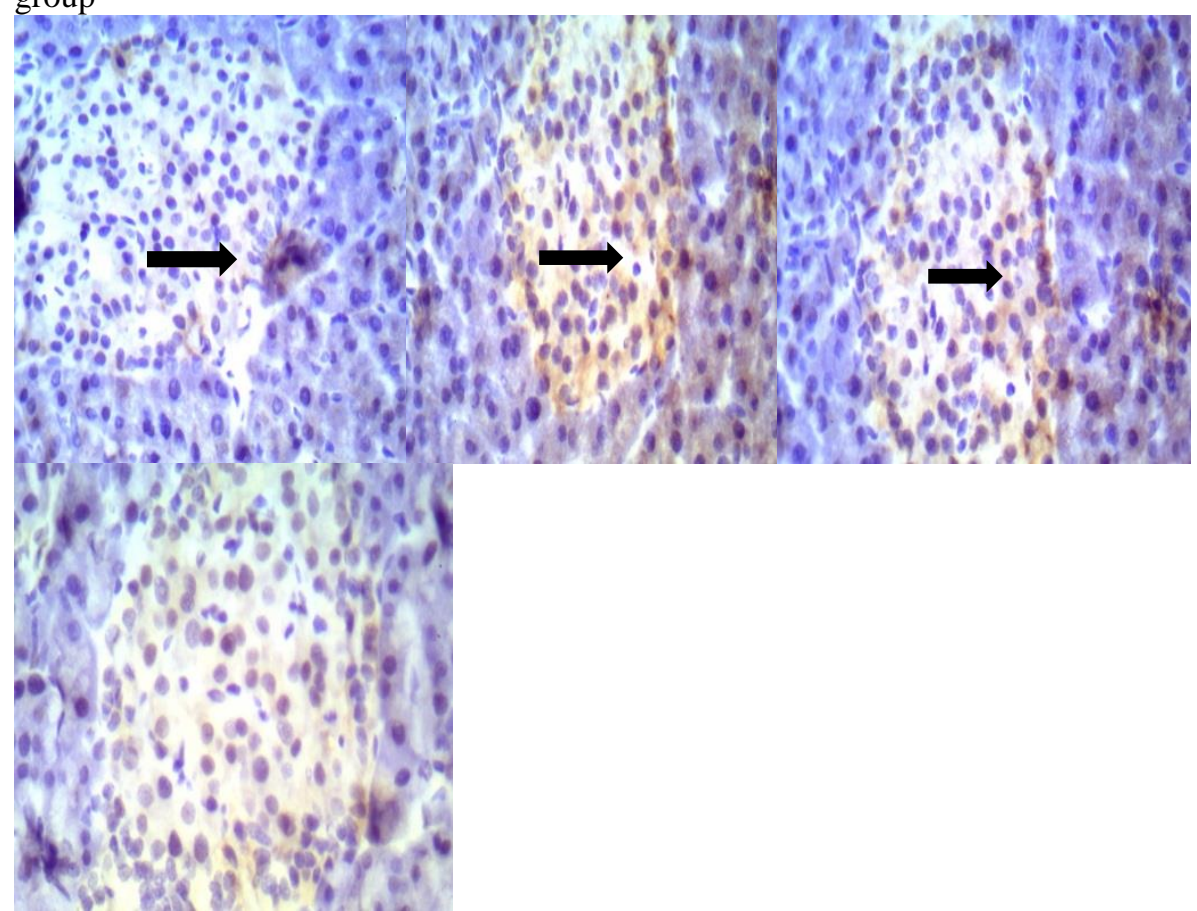

Fig. (6A-D) A photomicrograph of a section in pancreatic islets of a rat all experimental groups (Caspase-3 X 400). 
6(II) Estimation of caspase-3 marker in all experimental groups:

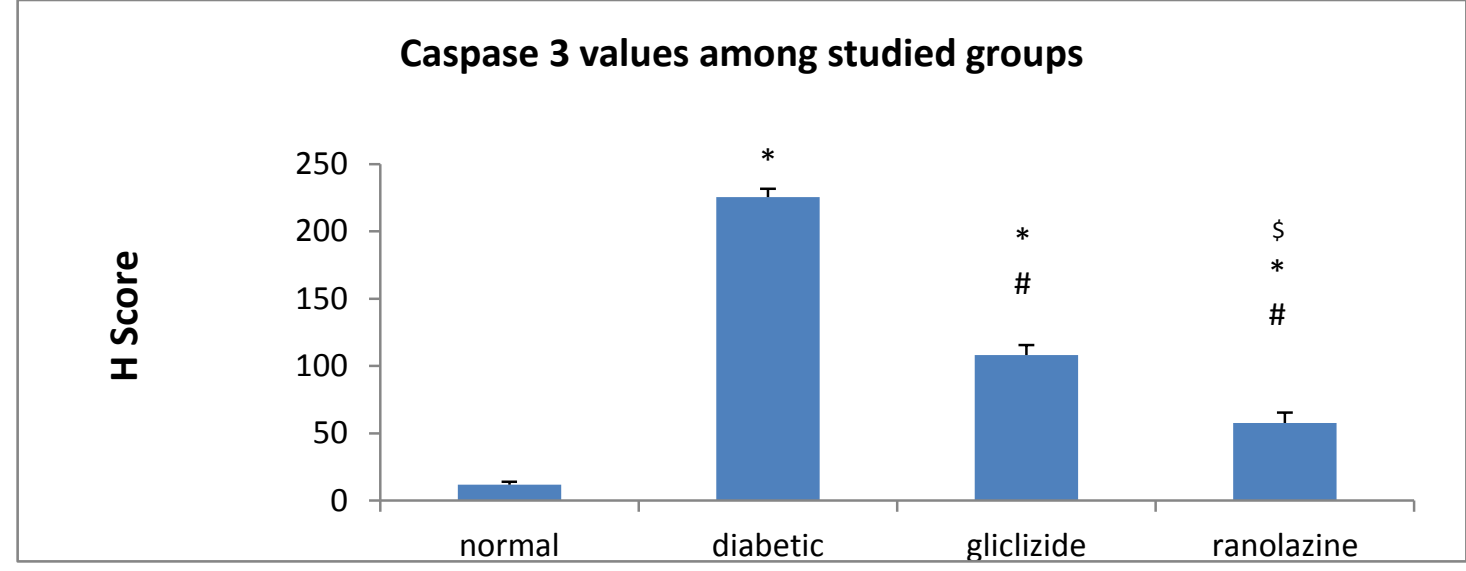

*Statistically significant difference versus normal control group $(P$-value $<0.05)$ \# Statistically significant difference versus diabetic control group $(P$-value $<0.05)$ $\$$ Statistically significant difference versus gliclazide-treated group (P-value $<0.05)$

\section{Discussion}

Ranolazine is a novel drug for angina which surges exercise duration and reduces frequency of anginal attacks in chronic angina patients. Ranolazine likewise has advantageous effects in diabetics as noticed by significant declines in $\mathrm{HbA}_{1 \mathrm{c}}$ in the clinical trials $[\mathbf{1 4 , 1 5}]$. This study was directed to assess the antidiabetic effect of ranolazine in HFD/STZ-challenged rats, which causes moderate hyperglycemia due to damage of pancreatic $\beta$-cells.

Streptozotocin (STZ) is a commonly powerful alkylating agent that yields a selective lethal effect on $\beta$-cells of pancreas and brings DM in most experimental animals. HFD followed by low dose STZ injection can trigger immune response and induce type $2 \mathrm{DM}$ as designated by the results of [16].

Gliclazide, which is used as a standard antidiabetic agent in the current study improved HFD/STZ-induced hyperglycemia via increasing insulin release from $\beta$-cells of pancreas and accelerating tissue uptake and consumption of glucose [17]. Ranolazine competently improved the harmful effects related to the HFD and low dose STZ as proven by reducing FBG level and $\mathrm{HbA}_{1 \mathrm{c}}[\mathbf{1 8}]$.

In accordance with [19] studies, the current study revealed that HFD/STZinduced hyperglycemia produced noticeable increased level of serum TG, TC 
and LDL- cholesterol (LDL-C) and decreased level of serum HDL cholesterol (HDL-C). One conceivable explanation could be afforded by [20] who highlighted that, this hyperlipidemia may be due to elevated level of cortisol and insulin insufficiency, which have an imperative role in fat accumulation process.

In agreement with [21], treatment with gliclazide proficiently lowered TC, TG and LDL-C concentrations and augmented HDL-C levels due to its stimulatory effect on the release of insulin. In accordance with [22,23], the current study shown that the HFD followed by low dose STZ produced hyperglycemia and hyperinsulinemia with subsequent surge in HOMA-IR index; that were competently ameliorated by treatment with either gliclazide or ranolazine.

Reactive oxygen species (ROS), nitric oxide, and peroxynitrite radicals, show an essential role in oxidative stress correlated to the pathogenesis of several important illnesses [24]. Vascular endothelial cells express iNOS in response to cytokines which produce NO that is involved in many inflammatory diseases [25]. Nitric oxide can react with ROS to produce vastly reactive oxidant species peroxynitrite; resulting in additional oxidative stress [26]. In accordance with the results of $[\mathbf{2 7 , 2 8}]$ who highlighted that diabetes was linked to amplified expression of iNOS and elevated nitric oxide levels in STZ-induced diabetic rats, our results showed that HFD/STZ-challenged rats exhibited elevation in NO serum level. Treatment with either gliclizide or ranolazine reinstated the balance by lowering the generation of free radical and elevating the free radical scavenging; resulting in reduction of NO levels.

Advanced glycated end products (AGEs) are involved in endothelial dysfunction [29]. The augmented formation of AGEs establishes a possible mechanism of hyperglycaemia-induced diabetic complications [30]. In accordance with $[31,32]$, our results revealed that gliclazide treatment 
competently lowered the augmented AGEs levels. Moreover, the current results revealed the antiglycation outcome of ranolazine on glucose-induced AGE formation.

High levels of free radicals can produce Products of Lipid peroxidation such as MDA which are significant in the pathogenesis of DM complication $[33,34]$. In the current study, a significant reduction in GSH, SOD and CAT and an elevation in MDA were observed in HFD/STZ-challenged rats. Treatment with either gliclazide or ranolazine produced a significant reduction in MDA and significant surge in GSH, SOD and CAT activity; reflecting the antioxidant characteristics of gliclazide and ranolazine. [35] revealed that gliclazide may lessen the oxidative stress via acting as a free radical scavenger [36]. Accordingly, the attained decreased expression of caspase- 3 is predictable and this outcome is in accordance with the results of [37] who reported that, the gliclazide's anti-apoptotic effect was linked to surge in protein kinase B level and a decline in caspase-3 levels. Treatment with ranolazine shows the same efficacy as that with gliclazide.

The histopathological analysis of the pancreas using H/E assured the biochemical markers and revealed the islets' collapse. In harmony with $[\mathbf{3 8 , 3 9}]$, the histopathological examinations of islets of pancreas in HFD/STZ-challenged rats showed hypocellularity, severe size shrinkage in association with deteriorating changes in pancreatic duct lining cells and significant surge in islet apoptosis rate in comparison to normal controls. These findings are confirmed by the immunohistochemical studies which revealed a surge in the apoptotic marker caspase-3.

In accordance with [40], the current study revealed that the administration of gliclazide to HFD/STZ-challenged rats significantly reduced the caspase-3 expression in pancreas. This finding supports the gliclazide's antioxidant role in 
mitigating the apoptosis in cells of pancreas. This could be explained by [41] who documented that, gliclizide could upregulate the antiapoptotic Bcl2 expression and downregulate the proapoptotic protein Bax expression.

The worsening of glycemic control in diabetes is supposed to be related to $\beta$-cell mass loss and progressive deterioration of $\beta$-cell function. The major finding of this study is that treatment with ranolazine decelerates the diabetes progression by reducing islets' apoptotic rate and preserving $\beta$-cell mass as proven by reduced caspase-3 level in HFD/STZ-challenged rats. Thus, the role of ranolazine in preservation of $\beta$-cell could be due to preservation of normal blood glucose level after HFD/STZ treatment. Another explanation could be afforded by [42] who stressed that ranolazine may apply advantageous effects on damage of beta cell, which is reliant on the cytosolic $\mathrm{Ca}^{2+}$. The cytosolic $\mathrm{Ca}^{2+}$ elevation surge antioxidatant enzymes and provide protection of beta-cells from the oxidative stress. Additionally, the augmented insulin sensitivity results in lowered blood glucose level and improvement of beta-cells environment.

In summary, the data from the current study reveals that ranolazine may apply possible ameliorating anti-diabetic effect by protecting $\beta$-cell mass and augmenting insulin sensetivity. In this setting, ranolazine has the potential to become a novel agent for treating patients with both diabetes and angina. Nevertheless, more pre-clinical studies are required to further describe the probable antidiabetic effect of ranolazine and its underlying molecular mechanisms. 


\section{Conclusion}

The results of this study showed that ranolazine improved diabetes by decreasing fasting blood glucose level, $\mathrm{HBA}_{1 \mathrm{c}}$, NO and AGEs. Moreover, it improved the oxidative stress markers, the histopathological picture of the pancreas and decreased the apoptosis.

\section{$\underline{\underline{\text { References }}}$}

[1] Wajchenberg BL (2007) beta-cell failure in diabetes and preservation by clinical treatment. Endocr Rev 28(2):187-218.

[2] Badran M. and Laher I (2012) Type II Diabetes Mellitus in ArabicSpeaking Countries. Int J Endocrinol 2012:1-11.

[3] Cannon CP (2008) Mixed dyslipidemia, metabolic syndrome, diabetes mellitus, and cardiovascular disease: clinical implications. Am J Cardiol 102(12A):5L-9L.

[4] Chaitman BR, Skettino SL, Parker JO, Hanley P, Meluzin J and et al (2004) Anti-ischemic effects and long-term survival during ranolazine monotherapy in patients with chronic severe angina. J Am Coll Cardiol 43(8):1375-82.

[5] Stone PH, Gratsiansky NA, Blokhin A, Huang IZ. and Meng L (2006) Antianginal Efficacy of Ranolazine When Added to Treatment With Amlodipine: The ERICA (Efficacy of Ranolazine in Chronic Angina) Trial. J Am Coll Cardiol 48(3):566-75.

[6] Chisholm JW, Goldfine AB, Dhalla AK, Braunwald E, Morrow DA and et al (2010) Effect of ranolazine on $\mathrm{A} 1 \mathrm{C}$ and glucose levels in hyperglycemic patients with non-ST elevation acute coronary syndrome. Diabetes Care 33(6):1163-8.

[7] Ning Y, Zhen W, Fu Z, Jiang J, Liu D and et al (2011) Ranolazine increases b-cell survival and improves glucose homeostasis in low-dose streptozotocin-induced diabetes in mice. J Pharmacol Exp Ther 337(1):50-8. 
[8] Fava D, Cassone-Faldetta M, Laurenti O, De Luca O, Ghiselli A. and et al (2002) Gliclazide improves anti-oxidant status and nitric oxide-mediated vasodilation in type 2 diabetes. Diabet Med 19(9):752-7.

[9] Srinivasan K, Viswanad B, Asrat L, Kaul CL. and Ramarao P (2005) Combination of high-fat diet-fed and low-dose streptozotocin-treated rat: A model for type 2 diabetes and pharmacological screening. Pharmacol Res 52(4):313-20.

[10] Lu HE, Jian CH, Chen SF, Chen TM, Lee ST and et al (2010) Hypoglycaemic effects of fermented mycelium of plaecilomyces farinosus (G30801) on high-fat fed rats with streptozotocin-induced diabetes. Indian J Med Res 131:696-701.

[11] Attia HN, Al-Rasheed NM, Al-Rasheed NM, Maklad YA, Ahmed AA and et al (2012) Protective effects of combined therapy of gliclazide with curcumin in experimental diabetic neuropathy in rats. Behav Pharmacol 23(2):153-61.

[12] Hennige AM, Burks DJ, Ozcan U, Kulkarni RN, Ye J and et al (2003) Upregulation of insulin receptor substrate-2 in pancreatic beta cells prevents diabetes. J Clin Invest 112(10):1521-32.

[13] Detre S, Saccani Jotti G. and Dowsett M (1995) A "quickscore" method for immunohistochemical semiquantitation: validation for oestrogen receptor in breast carcinomas. Clin Pathol 48:876-8.

[14] Timmis AD, Chaitman BR. and Crager M (2006) Effects of ranolazine on exercise tolerance and HbAlc in patients with chronic angina and diabetes. Eur Heart J 27(1):42-8.

[15] Scirica BM, Morrow DA, Hod H, Murphy SA, Belardinelli L and et al (2007) Effect of ranolazine, an antianginal agent with novel electrophysiological properties, on the incidence of arrhythmias in patients with non ST-segment elevation acute coronary syndrome: results from the metabolic efficiency with ranolazine for less ischemia in non ST-elevation acute coronary syndrome 
thrombolysis in myocardial infarction 36 (MERLIN-TIMI 36) randomized controlled trial. Circulation 116(15):1647-52.

[16] Papaccio G, Pisanti FA, Latronico MV, Ammendola E. and Galdieri M (2000) Multiple low dose and single high-dose treatments with streptozotocin do not generate nitric oxide. J Cell Biochem 77(1):82-91.

[17] Ojewole JA, Stephen O, Adewole SO. and Olayiwola G (2006) Hypoglycaemic and hypotensive effects of MomordicacharantiaLinn (Cucurbitaceae) whole-plant aqueous extract in rats. Cardiovasc J S Afr 17(5):227-32.

[18] Derr R, Garrett E, Stacy GA. and Saudek CD (2003) Is $\mathrm{HbA}(1 \mathrm{c})$ affected by glycemic instability? Diabetes Care 26(10):2728-33.

[19] Jurgonski A, Juskiewicz J. and Zdunczyk Z (2008) Ingestion of black chokeberry fruit extract leads to intestinal and systemic changes in a rat model of prediabetes and hyperlipidemia. Plant Foods Hum. Nutr 63(4):176-82.

[20] Hristova M. and Aloe L (2006) Metabolic syndrome - neuroirophic hypothesis. Med Hypotheses 66(3):545-9.

[21] Aquilante CL (2010) Sulfonylurea pharmacogenomics in Type 2 diabetes: the influence of drug target and diabetes risk polymorphisms. Expert Rev Cardiovasc Ther 8(3):359-72.

[22] Reed MJ, Meszaros K, Entes LJ, Claypool MD, Pinkett JG and et al (2000) A new rat model of type 2 diabetes: the fat-fed, streptozotocin-treated rat. Metabolism 49(11):1390-4.

[23] Zhang M, Lv XY, Li J, Xu ZG. and Chen L (2008) The characterization of high-fat diet and multiple low-dose streptozotocin induced type 2 diabetes rat model. Exp Diabetes Res 2008:704045.

[24] Shyur LF, Tsung JH, Chen JH, Chiu CY. and Lo CP (2005) Antioxidant properties of extracts from medicinal plants popularly used in Taiwan. Int $\mathbf{J}$ Appl Sci Eng 3(3):195-20. 
[25] Brinker AM, Ma J, Lipsky PE. and Raskin I (2007) Medicinal chemistry and pharmacology of genus Tripterygium (Celastraceae). Phytochemistry 68(6):732-66.

[26] Liorens S. and Nava E (2003) Cardiovascular diseases and the nitric oxide pathway. Curr Vasc Pharmacol 1(3):335-46.

[27] Stadler K, Jenei V, von Bölcsházy G, Somogyi A. and Jakus J (2003) Increased nitric oxide levels as an early sign of premature aging in diabetes. Free Radic Biol Med 35(10):1240-51.

[28] Madar Z, Kalet-Litman S. and Stark AH (2004) Inducible nitric oxide synthase activity and expression in liver and hepatocytes of diabetic rats. Pharmacology 73(2):106-12.

[29] Mashhoody T, Rastegar K. and Zal F (2014) Perindopril may improve the hippocampal reduced glutathione content in rats. Adv Pharm Bull 4(2):155-9. [30] Engelen L, Stehouwer CD. and Schalkwijk CG (2013) Current therapeutic interventions in the glycation pathway: evidence from clinical studies. Diabetes Obes Metab 15(8):677-89.

[31] Li W, Ota K, Nakamura J, Naruse K, Nakashima $E$ and et al (2008) Antiglycation effect of gliclazide on in vitro AGE formation from glucose and methylglyoxal. Exp Biol Med 233(2):176-9.

[32] Cardoso S, Santos RX, Correia SC, Carvalho C, Santos MS and et al (2013) Insulin-induced recurrent hypoglycemia exacerbates diabetic brain mitochondrial dysfunction and oxidative imbalance. Neurobiol Dis 49(1):1-12.

[33] Yazdanparast R, Ardestani A. and Jamshidi S (2007) Experimental diabetes treated with Achillea santolina: Effect on pancreatic oxidative parameters. J Ethnopharmacol 112(1):13-8.

[34] Halliwell B (2000) Lipid peroxidation, antioxidants and cardiovascular disease: how should we more forward? Cardiovasc Res 47(3):410-8. 
[35] Sliwinska A, Blasiak J, Kasznicki J. and Drzewoski J (2008) In vitro effect of gliclazide on DNA damage and repair in patients with type 2 diabetes mellitus (T2DM). Chem Biol Interact 173(3):159-65.

[36] Jennings PE (2000) Vascular benefits of gliclazide beyond glycemic control. Metabolism 49(10 Suppl 2):17-20.

[37] Li L. and Renier G (2009) The oral anti-diabetic agent, gliclazide, inhibits oxidized LDL-mediated LOX-1 expression, metalloproteinase-9 secretion and apoptosis in human aortic endothelial cells. Atherosclerosis 204(1):40-6.

[38] Adewole SO. and Ojewole JA (2007) Insulin-induced immuno histochemical and morphological changes in pancreatic beta-cells of streptozotocin-treated diabetic rats. Methods Find Exp Clin Pharmacol 29(7):447-55.

[39] Abo Gazia MM. and Hasan NM (2012) Effect of glabridin on the structure of ileum and pancreas in diabetic rats: A histological, immunohistochemical and ultrastructural study. Nat Sci 10 (3):78-90.

[40] Hanan A Soliman, Nadia A Eltablawy. and Mona S Hamed (2015) The ameliorative effect of Petroselinum crispum (parsley) on some diabetes complications. J Med Plants Stud 3(4):92-100.

[41] Del Guerra S, Grupillo M, Masini M, Lupi R, Bugliani M and et al (2007) Gliclazide protects human islet beta-cells from apoptosis induced by intermittent high glucose Diabetes Metab Res Rev 23(3):234-8.

[42] Drews G, Krippeit-DrewsP. and Dufer M (2010) Oxidative stress and beta-cell dysfunction. Pflugers Arch 460(4):703-18. 
Medicine Updates

Faculty of medicine

April 2020,volume 1, issue 1 https://muj.journals.ekb.eg

dean@med.psu.edu.eg

vice_dean_postgraduate@med.psu.edu.eg

DOI:10.21608/muj.2020.25071.1006

ISSN : 2682-2741

Submitted: $2 / 3 / 2020$

Accepted : 8/3/2020

Pages:29-41

\title{
Autologus Serum Therapy Efficacy as Adjunctive Treatment to Antihistaminics in Chronic Spontaneous Urticaria Patients
}

Heba A.Elsayed, Assisstant lecturer of Microbiology and jmmunblogy faculty of Medicin portsaid University, Egypt.

\begin{abstract}
Background: Chronic urticarial patients suffer from recurrent wheals which are severely itching for more than 6 weeks. The symptoms are more in auto-reactive urticaria $(\operatorname{arCU})$ where auto-antibodies in blood flares-up the condition.

Autologus serum skin test (ASST) is regarded of a great value in the primary assessment of patients' auto reactivity. Autologous serum therapy (AST) is a promising treatment modality for CSU patients with positive ASST by inducing desensitization to the pro-inflammatory mediators expressed in their blood.

Aim of the work: Improvement of chronic urticarial symptoms with a therapeutic option that is cheaper, safer and less risky than standard treatment options.

Patients and methods: Single-blind randomized controlled clinical trial study was done on $48 \mathrm{CU}$ patients (+ASST) and randomized into 2 groups; 24patients in cases group on anti-histamines will receive 9 weekly injections of AST and another 24 patients in control group will receive antihistamines alone for 9 weeks. We compared the urticarial activity score-7 of both groups at baseline,
\end{abstract}


fourth week, ninth week of treatment and at twelfth week of follow up after treatment to evaluate the efficacy of addition of AST to conventional treatment with antihistamines.

Results: The mean of UAS-7 was decreased in both treatment groups throughout the twelve weeks of treatment and follow up but the UAS-7 showed significant decrease in the cases group more than that of the control group from the fourth week onwards as $\mathrm{P}<0.05$.

Conclusion: In patients with arCU, AST is a useful adjunct to antihistamines which improves the urticarial symptoms.

Keywords: Chronic spontaneous urticaria, Autologous serum skin test, autoreactive urticarial, autologous serum therapy, chronic spontaneous urticaria.

\section{$\underline{\underline{\text { Introduction }}}$}

Patients with Chronic urticaria (CU) suffer from recurrent development of wheals which are severely itching and sometimes, these wheals are accompanied by angioedema lasting for more than 6 weeks, this condition occurs spontaneously in $80-90 \%$ of $\mathrm{CU}$ patients and is called chronic spontaneous urticaria (CSU) ${ }^{(1)}$. In $40-50 \%$ of CSU, there is evidence that IgG auto-antibodies to the alpha subunit of the Fc receptor of IgE molecule which is anti-FceR or, anti-IgE auto-antibodies can activate basophils to release histamine (2). Autologus serum skin test (ASST) is a skin reaction of erythematous and/or wheal-type in response to the autologous serum which indicates the presence of autoantibodies, which may be responsible for the mast cells degranulation ${ }^{(3)}$. Standard treatment of CSU is directed towards symptom control by second generation antihistamines against the $\mathrm{H} 1$ receptors but only $40 \%$ of those patients experienced complete clearing of their symptoms (4). Options for refractory CSU as immunosuppressive agents as (corticosteroids, cyclosporine), methotrexate and omalizumab are limited by factors like need for prolonged therapy, fatal side effects, presence of associated disorders, need for continous 
laboratory testing, regular patient monitoring, and high cost of therapy ${ }^{(5)}$. Autologous serum therapy (AST) is a promising treatment modality for CSU patients with positive ASST by inducing tolerisation or desensitization to the pro-inflammatory mediators expressed in their blood ${ }^{(6)}$.

\section{Patients and Methods}

The study was a single-blind randomized controlled clinical trial done between January and May 2015. During the study period, seventy-four patients with CSU who attended the Allergy outpatient clinic, Dermatology outpatient clinic at SCUH and El-Sheikh Zaid Dermatology Clinic were included in our study after obtaining approval of Local Research Ethics Committee and written informed consent was taken from each one of study participants. Patients who were less than 12 years, pregnant, lactating mothers, suffering from immunosuppression due to drug or disease, hepatitis B or C patients were not included in our study. A detailed history and physical examination were done for all the patients. All patients were asked to stop antihistamines 2 days before the ASST test was done on all the 74 patients. Only 48 patients who were ASST+ve patients were only included in this study.

Autologus serum skin test (ASST):

Five milliliters venous blood was taken from all patients by using sterile 27gauge 10-ml syringes. The blood samples were placed in glass tubes without anticoagulants. Collected venous blood was stored at room temperature for 30 minutes and subsequently centrifuged for 10 minutes at $3000 \mathrm{rpm}$. After cleansing areas of both forearm, $0.05 \mathrm{ml}$ of physiologic saline (as negative control) and $0.05 \mathrm{ml}$ of autologous serum were injected $5 \mathrm{~cm}$ apart on the right forearmand another intradermal injection of $0.05 \mathrm{ml}$ histamine on the left forearm (as a positive control) to create a papule to prevent interference between the erythemas and swellings caused by the autologous serum and histamine. 
The injection was considered to have been administered too deep, If a papule was not observed after the injection, and should be repeated after 2 days. After 30 minutes, the results were evaluated. The interpretation of results was done by measuring the swelling diameter as the mean between the widest diameter and perpendicular diameter. If the diameter of swelling resulting from the autologous serum exceeded that from physiologic saline injection by $1.5 \mathrm{~mm}$, the swelling was defined as positive.

The test result was considered negative, if there were erythema without swelling, so that the test should be repeated after another 30 minutes. If there was no reaction at all after 60 minutes, the test was evaluated as negative ${ }^{(7)}$.

Forty-eight patients were enrolled in the study and randomized by computer generated random numbers into two groups: cases group (AST group) who were $24 \mathrm{CSU}$ patients and treated with 9 deep intramuscular gluteal injection of autologous serum once weekly in addition to their conventional treatment with antihistamines (cetirizine $10 \mathrm{mg}$ ) and control group (conventional therapy group) who were 24 CSU patients and treated with conventional therapy with oral H1 antihistamines only (cetirizine $10 \mathrm{mg}$ ).

Autologous serum therapy:

Five $\mathrm{ml}$ venous blood of the patient was drawn with a sterile, disposable syringe from the antecubital vein, then blood was centrifuged for $10 \mathrm{~min}$ (3000 rpm), and $2 \mathrm{ml}$ of the serum was injected deep intramuscularly into the gluteus muscle with a $27 \mathrm{G}$ needle. The procedure was repeated for 8 weeks ${ }^{(8)}$.

Effectiveness parameters:

The primary outcome measures for effectiveness were Urticaria activity score-7. UAS is used widely in patients with CSU that includes 2 items: number of hives and intensity of pruritus. Items were scored individually, and the UAS-7 was 
calculated as the sum of pruritus intensity and number of hives over 1 week before the day of blood sampling. Patients themselves documented a 24-h selfevaluation scores for 7 days applying the following scheme: no wheals $=0,<20$ wheals $/ 24 \mathrm{~h}=1,20-50$ wheals $/ 24 \mathrm{~h}=2,>50$ wheals $/ 24 \mathrm{~h}=3$ and pruritus intensity: no $=0$, mild $=1$, moderate $=2$, severe $=3$. Weekly UAS equals the sum score of 7 consecutive days with a minimum score of 0 and a maximum score of 42. Consequently, weekly UAS will be graded as follows: 0-14 (mild), 15-29 (moderate) and 30-42 (severe) ${ }^{(9)}$.

Safety parameters:

Specialized staff of the Allergy and Immunology should observe AST. Department with a period of half an hour to observe any complications as swelling, difficulty in breathing, nausea or signs of shock as hypotension taking all the required precautions by preparing two ampoules of adrenaline $1 \mathrm{mg} / \mathrm{ml}$, and one ampoule of antihistamines as promethazine or diphenhydramine. Sterile injection technique is recommended. Proper labeling and injection technique were advised to avoid infection transfer.

Statistical analysis:

Statistical analysis: All the grouped data was statistically evaluated using SPSS (statistical package for social sciences) program (windows version number 11). All values were presented as means +/- SD. Data derived from the two groups were evaluated by one - way analysis of variance (ANOVA). Difference between two groups was compared by Mann-Whitney U Test. Data was considered statistically significant with a $\mathrm{P}$ value $<0.05$.

\section{$\underline{\underline{\text { Results }}}$}

Among 74 study participants, 48 were randomized equally into two groups. In this study, females outnumbered males in both groups as in cases group $4 \%$ of 
patients were males and $96 \%$ were females, while in control group $8.3 \%$ were males and $91.6 \%$ were females. The age was comparable in both cases and control groups as ranged from 18 to 44 years in cases group with mean of 32.6 years and from 14 to 42 years in control group with mean of 32.6 years. The disease duration was comparable between cases and control groups as was ranged from 4 months to10 years in cases with mean of 4.4years, while in control group was ranged between 6 months to12 years with mean of $4.5 y e a r s$. UAS was comparable at baseline, and decreased in both groups. However; intergroup comparison revealed that the decrease was significantly more in the AST group from $4^{\text {th }}$ follow-up and was evident till end of follow up. At baseline, there was no significant statistical difference in total UAS-7 score between the both treatment groups, where the mean of UAS-7 for cases group was 36.7 and the control group was 34.5 . At the $4^{\text {th }}$ week, the mean of UAS-7 of cases group was decreased from 36.7 at baseline to become 17.1 at the $4^{\text {th }}$ week. But in the control group, the mean of UAS-7 was decreased from 34.5 at baseline to become 28.6 at the fourth week. At the ninth week, there was significant statistical difference in UAS-7 mean between both groups as the mean of UAS-7 of cases group was 10.2. But in the control group, the mean of UAS-7 was 21.1. After 12 weeks from completion of treatment, the mean of UAS-7 remained decreasing in the cases group to reach 8.8, so they showed tolerance even after discontinuation of injection. But in the control group, the mean of total UAS-7 was 16.4. To clarify the influence of adding AST to antihistamines in cases group, we compared the mean of UAS-7 throughout the weeks of treatment and follow up and we founded significant decline in UAS-7 accompanied by significant improvement in urticarial symptoms at the fourth week compared to baseline, at the ninth week compared to the fourth week and at the twelfth week compared to the ninth week. 
On the contrary, the control group who received antihistamines only and by comparing the mean of UAS-7 throughout the weeks of treatment, we founded no significant decline in UAS-7 throughout the weeks of treatment and follow up except at the 9th week as compared to the 4th week.

\section{Tables and Figures:}

Table 1: Demographic data of the studied groups regarding age, urticarial duration, sex, residence and education level.

\begin{tabular}{|l|c|c|c|}
\hline & $\begin{array}{c}\text { Cases group } \\
\mathbf{( 2 4 )}\end{array}$ & $\begin{array}{c}\text { Control group } \\
\mathbf{( 2 4 )}\end{array}$ & P value \\
\hline Age (years) & $32.6 \pm 8.3$ & $32.6 \pm 8.3$ & 1.000 \\
Mean \pm SD & $18-44$ & $14-42$ & \\
Range & & & \\
\hline Urticaria & & $4.5 \pm 6.6$ & 0.850 \\
duration (years) & $4.4 \pm 5.9$ & $0.5-12$ & 0.283 \\
Mean \pm SD & $0.33-10$ & $2(8.3 \%)$ & \\
Range & $1(4 \%)$ & $22(91.6 \%)$ & \\
\hline $\begin{array}{l}\text { Gender (\%) } \\
\text { Males }\end{array}$ & $23(96 \%)$ & Females & \\
\hline
\end{tabular}

Table 2: Comparison between the mean of UAS-7 of the two studied groups through weeks of treatment and follow up.

\begin{tabular}{|c|c|c|c|}
\hline & $\begin{array}{c}\text { Cases group } \\
\text { (24) }\end{array}$ & $\begin{array}{c}\text { Control group } \\
\text { (24) }\end{array}$ & P value \\
\hline $\begin{array}{l}\text { Age (years) } \\
\text { Mean } \pm \text { SD } \\
\text { Range }\end{array}$ & $\begin{array}{c}32.6 \pm 8.3 \\
18-44\end{array}$ & $\begin{array}{c}32.6 \pm 8.3 \\
14-42\end{array}$ & 1.000 \\
\hline $\begin{array}{l}\text { Urticaria } \\
\text { duration (years) } \\
\text { Mean } \pm \text { SD } \\
\text { Range }\end{array}$ & $\begin{array}{l}4.4 \pm 5.9 \\
0.33-10\end{array}$ & $\begin{array}{c}4.5 \pm 6.6 \\
0.5-12\end{array}$ & 0.850 \\
\hline $\begin{array}{l}\text { Gender (\%) } \\
\text { Males } \\
\text { Females }\end{array}$ & $\begin{array}{c}1(4 \%) \\
23(96 \%)\end{array}$ & $\begin{array}{c}2(8.3 \%) \\
22(91.6 \%)\end{array}$ & 0.283 \\
\hline $\begin{array}{l}\text { Residence (\%) } \\
\text { Urban } \\
\text { Rural }\end{array}$ & $\begin{array}{c}7(30 \%) \\
17(70 \%)\end{array}$ & $\begin{array}{l}11(45 \%) \\
13(55 \%)\end{array}$ & 0.176 \\
\hline $\begin{array}{l}\text { Educational } \\
\text { level }(\%) \\
\text { Literate } \\
\text { Illiterate }\end{array}$ & $\begin{array}{c}5(22.2 \%) \\
19(77.8 \%)\end{array}$ & $\begin{array}{l}10(40.35 \%) \\
14(59.65 \%)\end{array}$ & 0.076 \\
\hline
\end{tabular}


Figure 1: Comparison between the mean of UAS-7 of the two studied groups through weeks of treatment and follow up.

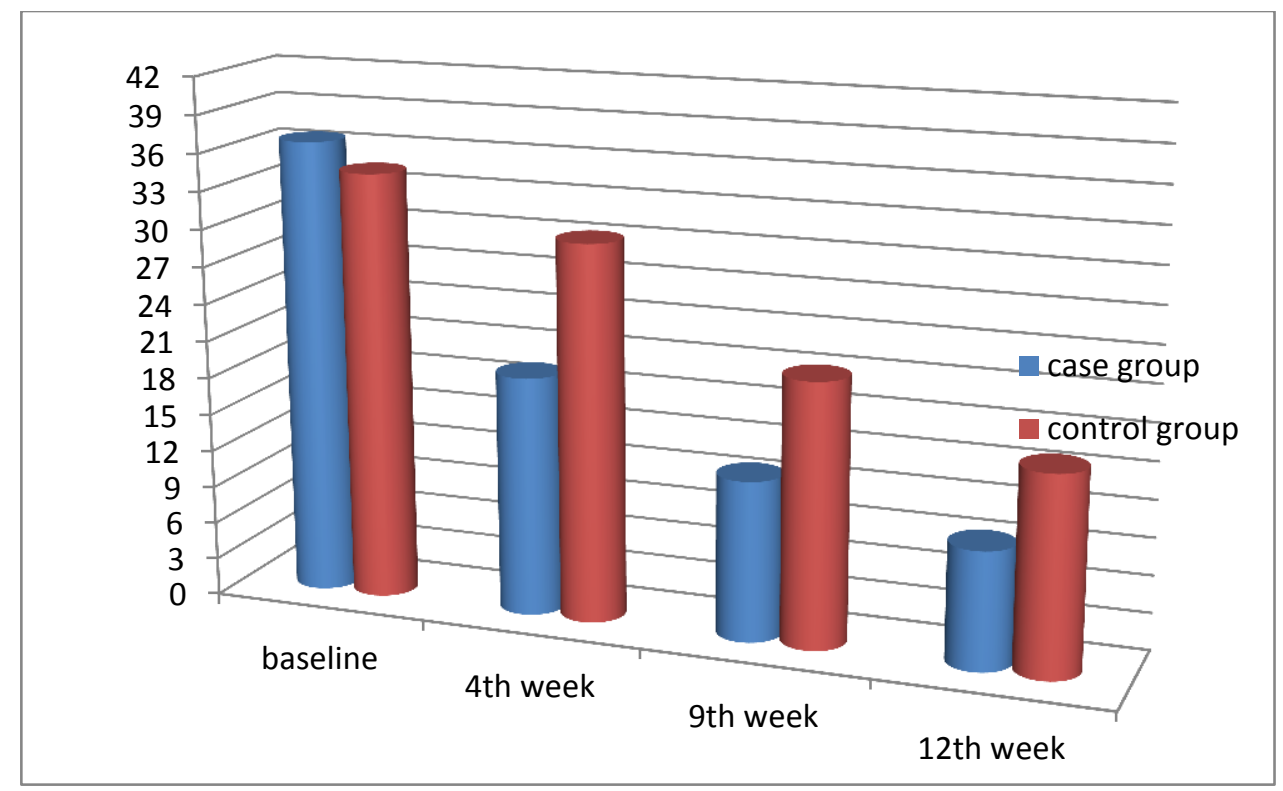

Table 3: Differences in mean UAS-7 throughout weeks of treatment of cases group

\begin{tabular}{|l|l|l|}
\hline & \multicolumn{1}{|c|}{$\begin{array}{c}\text { Cases group } \\
(\mathbf{2 4})\end{array}$} & $\begin{array}{l}\text { P value of mean } \\
\text { difference }\end{array}$ \\
\hline $\begin{array}{l}\text { Baseline UAS-7 } \\
\text { Mean } \pm \text { SD }\end{array}$ & $36.7 \pm 8.7$ & \\
\hline $\begin{array}{l}\mathbf{4}^{\text {th }} \text { week UAS-7 } \\
\text { Mean } \pm \text { SD }\end{array}$ & $17.1 \pm 14.9$ & $<\mathbf{0 . 0 0 1}^{*}$ \\
\hline $\begin{array}{l}\mathbf{9}^{\text {th }} \text { week UAS-7 } \\
\text { Mean } \pm \text { SD }\end{array}$ & $10.2 \pm 16.7$ & $\mathbf{0 . 0 0 3}^{*}$ \\
\hline $\begin{array}{l}\mathbf{1 2}^{\text {th }} \text { week UAS_7 } \\
\text { Mean } \pm \text { SD }\end{array}$ & $8.8 \pm 14.4$ & $\mathbf{0 . 0 0 3}^{*}$ \\
\hline
\end{tabular}

Table 4: Differences in mean UAS-7 throughout weeks of treatment of control group

\begin{tabular}{|l|l|l|}
\hline & \multicolumn{1}{|c|}{$\begin{array}{c}\text { Cases group } \\
(\mathbf{2 4})\end{array}$} & P value of mean difference \\
\hline $\begin{array}{l}\text { Baseline UAS-7 } \\
\text { Mean } \pm \text { SD }\end{array}$ & $36.7 \pm 8.7$ & \\
\hline $\begin{array}{l}\mathbf{4}^{\text {th }} \text { week UAS-7 } \\
\text { Mean } \pm \text { SD }\end{array}$ & $17.1 \pm 14.9$ & $<\mathbf{0 . 0 0 1}^{*}$ \\
\hline $\begin{array}{l}\mathbf{9}^{\text {th }} \text { week UAS-7 } \\
\text { Mean } \pm \text { SD }\end{array}$ & $10.2 \pm 16.7$ & $\mathbf{0 . 0 0 3}^{*}$ \\
\hline $\begin{array}{l}\mathbf{1 2}^{\text {th }} \text { week UAS_7 } \\
\text { Mean } \pm \text { SD }\end{array}$ & $8.8 \pm 14.4$ & $\mathbf{0 . 0 0 3}^{*}$ \\
\hline
\end{tabular}


Figure 2: Comparison between the mean of UAS-7 of the two studied groups through weeks of treatment and follow up.

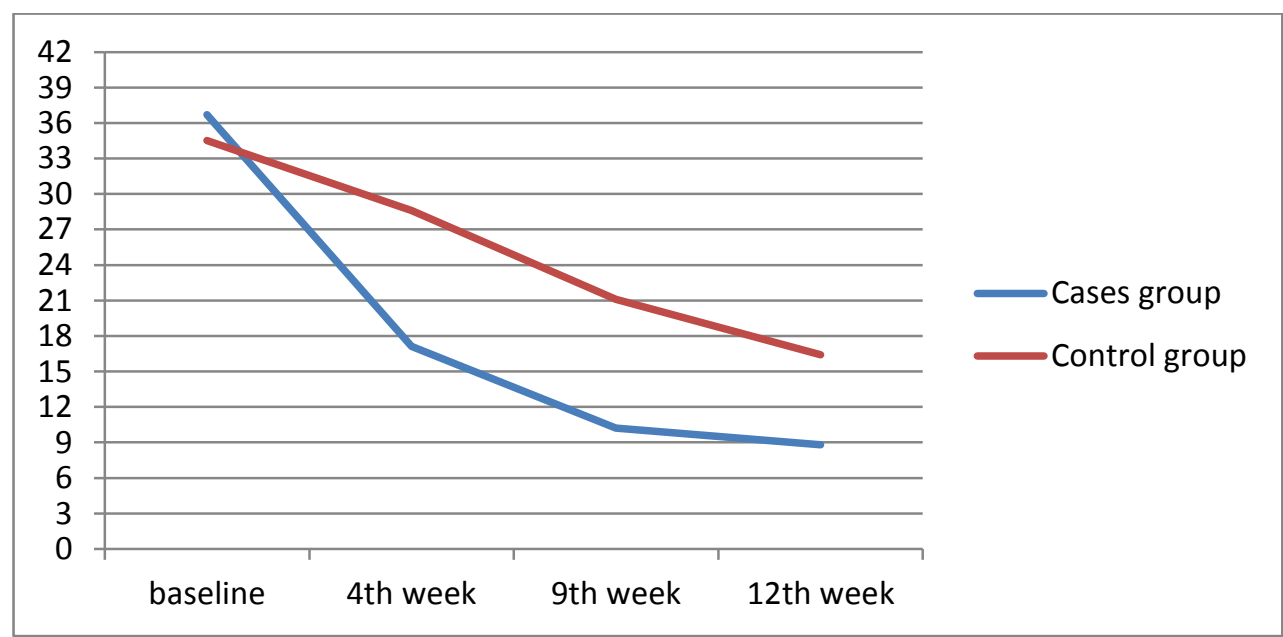

\section{$\underline{\underline{\text { Discussion }}}$}

$\mathrm{CU}$ is a common problem and negatively affects both social life and work negatively because of its chronic annoying course and poor therapy response.

Today, we know that up to $50 \%$ of CU may be arCU (10). ASST is an in vivo test that assesses auto reactivity in arCU patients, particularly during the active phases of the disease (11). The pharmacotherapy for urticaria depends on two important modes of action; the first is to neutralize the effect of products of degranulation and the other is to prevent degranulation.

Antihistamines and leukotriene inhibitors, are the mainstay for urticaria management but sometimes, they are insufficient in controlling urticaria. So we have to use immunosuppressive agents (e.g., corticosteroids, cyclosporine, methotrexate, adalimumab etc.) to control urticaria symptoms and they aim to prevent degranulation by preventing antibody formation.

The use of immunosuppressive agents is limited by their side-effect profile(s) and/or by their expensive cost (12). Our study showed a female predominance, similar to previous reports (13). In our study, age was comparable in both cases and control groups as ranged from 18 to 44 years in cases group with mean of 
32.6 years and from 14 to 42 years in the control group with mean of 32.6 years. These results are also consistent with Debberman et al. (2014) regarding age as the mean of age in cases group was 39.5 years and in control group was 38.2 years with no significant statistical difference between both groups ${ }^{(13)}$. Our study showed that mean UAS-7 was nearly approximate in both groups at baseline, but there was significant decrease in mean UAS-7 in cases group as compared to control group at 4th week, 9th week of treatment and 12th week of follow. These results is consistent with a study done by Debbarman et al. (13) as they found that UAS-7 was comparable at baseline, and then decreased in both groups.

However; the comparison between both groups revealed significant decrease in UAS-7 in the AST group from 4 th week and till the end of six months of follow up. This study is consistent also with Patil et al. (14) who found that UAS-7 comes down within a few weeks. This study is consistent with the study done by Bajaj et al., (8) who founded that almost $60 \%$ of ASST (+) patients show a significant improvement in their signs and symptoms after nine weekly ASTs are given. This study is also consistent also with a study done in Egypt by Abdallah et al., (15) which concluded that both AWB and AST are effective in controlling urticarial symptoms in a significant number of ASST-positive patients.

They found that in in AST group, 60\% were cured or had mild urticarial symptoms in 12th week. Kocaturk et al. (16) did not agree that this treatment method might represent a means of inducing specific tolerizing immune responses similar to those seen in specific immunotherapy; because the effect of treatment was more obvious during the injection period than after the injections were discontinued.

However, our study might have disagreed because Kocaturk et al included both ASST + and ASST - cases. 
Finally, AST proved itself as an excellent adjuvant therapy because it reduced the urtcarial symptoms. AST was well-tolerated and only a few patients reported minor side effects as rash, itching and dizziness just after the first injection in 6 cases (25\%) and AST as immunotherapy may predispose to autoimmunity disorders later on.

\section{$\underline{\underline{\text { References }}}$}

1-Zuberbier T, Maurer M. (2015). Omalizumab for the treatment of chronic urticaria. Expert Review of Clinical Immunology; 11: 171-180.

2- Kaplan AP, Greaves M. (2009). Pathogenesis of chronic urticaria. Clinical and Experimental Allergy; 39: 777-87.

3- Konstantinou GN, Asero R, Maurer M, Sabroe RA, Schmid Grendelmeier P, Grattan CEH. (2009). EAACI/GA2LEN task force consensus report: the autologous serum skin test in urticaria. Allergy; 1256-1268.

4- Asero R, Tedeschi A and Riboldi P. (2006). Plasma of patients with chronic urticaria shows signs of thrombin generation, and its intradermal injection causes wheal and-flare reactions much more frequently than autologous serum. Journal of Allergy and Clinical Immunology; 117:1113-7.

5- Powell RJ, Du Toit GL, Siddique N, Leech SC, Dixon TA, Clark AT. (2007). BSACI (British Society for Allergy and Clinical Immunology) guidelines for the management of chronic urticaria and angioedema. Clinical \& Experimental Allergy; 37:631-50.

6- Staubach P, Onnen K, Vonend A, Metz M, Siebenhaar F, Tschentscher I. (2006). Autologous Whole Blood Injections to Patients with 
Chronic Urticaria and a Positive Autologous Serum Skin Test: A PlaceboControlled Trial. Dermatology; 212: 150-9.

7- European Academy of Allergy and Clinical Immunology (EAACI). (2014). Anaphylaxis: guidelines from the European Academy of Allergy and Clinical Immunology.

8- Bajaj AK, Saraswat A, Upadhyay A, Damisetty R, Dhar S. (2008). Autologous serum therapy in chronic urticaria: Old wine in a new bottle. Indian Journal of Dermatology; 74 (2): 109-13.

9- Mathias SD, Crosby RD, Zazzali JL, Maurer M, Saini SS. (2012). Evaluating the minimally important difference of the urticarial activity score and other measures of disease activity in patients with chronic urticarial. Annals of Allergy Asthma and Immunology; 108(1):20-4.

10- Najib U, Sheikh J. (2009). The spectrum of chronic urticarial. Allergy and Asthma Proceedings; 1-10(10).

11- Abd El-Azim M, Abd El-Azim S. (2011). Chronic Autoimmune Urticaria: Frequency and Association With Immunological Markers. Journal of Investigative Allergology and Clinical Immunology; Vol. 21(7): 546-550.

12- Zuberbier T, Asero R, Canonica WG, Bindslev-Jensen C, Church MK, Giménez-Arnau AM. (2009). : EAACI/GA2LEN/EDF/WAO guideline: management of urticaria. Allergy; 64: 1427.

13- Debbarman P, Amrita S, Piyush KD, Debabrata B, Nilay K. (2014). Autologous serum therapy in chronic urticaria: A promising complement to antihistamines. Indian Journal of Dermatology; 375-382.

14- PatilS, Nidhi S, Kiran G. (2013). Autologous Serum Therapy in Chronic Urticaria. Indian Journal of Dermatology; 58(3): 225-226. 
15- Abdallah M, Elzamek M, Sallam M, Mohamed A. (2012). Autologus serum injection versus autologous blood in the treatment of chronic autoreactive urticaria. Journal of Egyptian Women's Dermatologic Society; Volume 9; 26-31.

16- Kocatürk E, Aktaş S, Türkoğlu Z, Kavala M, Zindanci I, Koc M. (2011). Autologous whole blood and autologous serum injections are equally effective as placebo injections in reducing disease activity in patients with chronic spontaneous urticaria. Journal of Dermatological Treatment; 23 (6): 465-71. 
Medicine Updates

Faculty of medicine

April 2020,volume 1, issue 1 https://muj.journals.ekb.eg

dean@med.psu.edu.eg

vice_dean_postgraduate@med.psu.edu.eg

DOI:10.21608/muj.2020.25068.1008

ISSN : 2682-2741

Submitted: $\mathbf{3 / 3 / 2 0 2 0}$

Accepted : 9/3/2020

Pages:42-54

\section{Evaluation of Cardiac Troponin I as a Non Invasive Tool for Diagnosis of the Newborns and Infants Below 6 Months with Congenital Heart Diseases}

Mohamed Abd elrahman, ( Resident, Department of paediatrics and neonatology) Faculty of Medicine Suez Canal University; Ismailia, Egypt.

\section{Abstract}

\section{Background}

Congenital heart diseases accounts for nearly one third of all major congenital anomalies. Different modalities for diagnosis of CHD are available, in spite of that only $73 \%$ can be diagnosed before discharge from hospital, while $27 \%$ discharged without diagnosis. There is an increasing need for new diagnostic modalities to help early diagnosis and screening of CHD, biomarkers as cardiac troponin I represents an excellent choice.

$\underline{\underline{\text { Aim }}}$

The aim of this study is to find new, easy and noninvasive diagnostic modalities for earlier detection of congenital heart diseases.

\section{Patients /Methods}

The study was case control study. The study involved 50 cases. cases will be divided into 2 main groups: group (1) 25 patients with congenital heart diseases confirmed by echocardiography, group (2) (control) 25 healthy newborns and infants, patients with CHD in group (1) was further divided into 2 subgroups: 
group (1a) patients with simple shunts, group (1b) patients with combined defects. Each case was subjected to complete history, physical examination, and peripheral blood samples were withdrawn and cardiac troponin I level was measured.

\section{$\underline{\underline{\text { Results }}}$}

Serum level of cardiac troponin I (cTnI) was higher in the diseased group compared to the control group, and is higher in patients with complex defects compared to patients with simple shunts. The sensitivity of the test was $72 \%$ and the specificity was $92 \%$.

\section{Conclusion}

Serum cTnI level was found to have a statistically significant association with congenital heart disease, being higher in complex defects than simple shunts.

Key words: cTnI, CHD, biomarkers.

\section{Introduction:}

Congenital heart diseases (CHD) accounts for nearly one third of all major congenital anomalies, its incidence increased from 0.6 per 1000 live births at 1930 to 9.1 per 1000 live births after $1995^{(1)}$, in Egypt the prenatal incidence of moderate and severe cardiac anomalies reaches 19 per 1000 live children ${ }^{(2)}$. Also there is an increase in the median age of patients with CHD, it was 11 years in 1985,17 years in 2000 and reach 25 years in 2010 , the proportion of adults with CHD increased from $54 \%$ in 2000 to $66 \%$ in $2010^{(3)}$.

This increase is mainly due to increased awareness about CHD, development of new modalities for diagnosis, improved care and decreased mortality ${ }^{(4)}$, also there is increased incidence due to increased maternal age ${ }^{(5)}$, excessive body mass index (BMI) and maternal smoking during pregnancy ${ }^{(6,7)}$.

Different modalities for diagnosis of CHD are available, in spite of that only $73 \%$ of cases can be diagnosed before discharge from hospital, while $27 \%$ of cases discharged from hospital without diagnosis ${ }^{(\mathbf{8})}$. 
This delay in diagnosis strongly affects preoperative condition of the patient, which in turn affects postoperative progress and mortality, so early diagnosis of CHD is essential to decrease mortality rate ${ }^{(9,10)}$. There is an increasing need for new diagnostic modalities to help early diagnosis and screening of CHD, biomarkers as cardiac troponin I represents an excellent choice as it is easy test can be done wherever, needs no special centers as catheterization, no skilled cardiologist as echocardiography ${ }^{(11)}$.

Recent studies showed that variable biomarkers can be used as indicators for pressure and volume overload that occur in CHD such as cardiac troponin I (cTnI), cardiac troponin $\mathrm{T}(\mathrm{cTnT}), \mathrm{N}$-terminal pro brain natriuretic peptide (NTproBNP), heart-type fatty acid binding protein (H-FABP) and high-sensitivity Creactive protein (Hs-CRP) ${ }^{(12,13,14)}$.

Troponin complex comprises troponin $\mathrm{C}$, troponin $\mathrm{T}$ and troponin I; of these cardiac troponins $\mathrm{T}$ and $\mathrm{I}$ are myofibrillar regulatory proteins which are highly specific to cardiac tissue and only small portions present in cytosol while the majority is bound to contractile proteins. Cardiac troponin I can be used as a marker for cardiac injury with high sensitivity (95.5\%), specificity (97.1\%), positive predictive value (96\%) and negative predictive value $(99.1 \%){ }^{(15,16)}$. Also cardiac troponin I can be used as a useful biomarker for evaluating myocardial damage in CHD caused by volume and pressure overload ${ }^{(17,18,19)}$.

In this study researcher will evaluate cardiac troponin I as a diagnostic tool for CHD aiming to facilitate early diagnosis of CHD.

\section{Patients \& Methods:}

The study was case control study. The study population was sampled from neonates and infants (aging $<6$ month) admitted to Suez Canal University Hospital's neonatal intensive care unit (NICU), pediatric intensive care unit (PICU) and pediatrics inpatient from September 2015 to March 2016. Simple random sampling was used. every patient admitted to the SCU Hospital eligible for the study`s criteria was chosen. Exclusion criteria includes any neonate suggested to be exposed to severe perinatal asphyxia (Apgar score $<4$ in $1^{\text {st }}$ and $5^{\text {th }}$ minute), neonates and infants below 6 months with signs of severe non cardiac illness (as septic shock) and patients with myocardial diseases (as toxic myocarditis). 
The study involved 50 cases. cases were divided into 2 main groups : group 1 (cases) consisted of 25 patients with congenital heart diseases confirmed by echocardiography, group 2 (control) consisted of 25 healthy newborns and infants who were age and sex matching the cases, they were collected from newborns and infant admitted to SCU hospital for non-cardiac cause, patients with CHD in group (1) was further divided into 2 subgroups: group (1a) patients with simple shunts (ASD, VSD , PDA or combinations of these lesions ), group (1b) patients with combined defects (others).

Detailed medical history was taken, detailed physical examination and basic laboratory tests were performed for each case. Troponin I was evaluated using PATHFAST ${ }^{\circledR}$ Troponin I (Mitsubishi, Japan). $1 \mathrm{ml}$ of blood was collected using standard sampling tubes, the collected samples was centrifuged to remove the coagulated or packed cells within 60 minutes after collection, samples was frozen at $-20^{\circ} \mathrm{c}$ or lower, freeze only once, Storage and assays were performed as per the manufacturer's protocol.

The data was recorded in a case sheet, the case sheet was divided into five sections: personal data, perinatal data, clinical data, laboratory data and radiological data including chest $\mathrm{x}$-ray and echocardiography.

Statistical analysis was done by Statistical Package for Social Science (SPSS) for windows version 22. The distribution of variables was compared with the normal distribution by means of the Kolmogorov-Smirnov goodness-of-fit test. The differences between groups in non-parametric quantitative data were assessed by Mann-Whitney $U$-test and Kruskal Wallis test. Chi-square test was used for testing significant differences of qualitative variables. For cross-tables were the number of cells whose expected count less than 5 were $>20 \%$ of cells, Fisher's Exact tests and Exact $p$ value for Chi-square test were used. ROC curve was used to assess the sensitivity, specificity and accuracy of cTnI as a marker of myocardial injury in patients with CHD. For all statistical analysis the level of significance considered was $<0.05$. 


\section{$\underline{\underline{\text { Results }}}$}

Table 1. Mean value and standard deviation of cTnI in different groups.

\begin{tabular}{|l|c|c|c|}
\hline & Mean \pm Std. Deviation & Range & \multirow{2}{*}{ P value } \\
\cline { 1 - 3 } Normal (n=25) & $0.01 \pm 0.00 \mathrm{ng} / \mathrm{ml}$ & $0.006-0.014$ & $0.01-0.77$ \\
\cline { 1 - 3 } Simple CHD (n=14) & $0.23 \pm 0.32 \mathrm{ng} / \mathrm{ml}$ & $0.001 *$ \\
\cline { 1 - 2 } Complex CHD (n=11) & $0.99 \pm 0.19 \mathrm{ng} / \mathrm{ml}$ & $0.78-1.32$ & \\
\hline
\end{tabular}

* Statistically significant at $\mathrm{p}<0.05$, Mann-Whitney U test

This table shows the mean value \pm standard deviation of $\mathrm{cTnI}$ in the different groups. It was higher in the neonates and infants with CHD than in healthy neonates and infants in the control group being higher in patients with complex defects than in patients with simple shunts. (P value $=<0.001$ ).

Table 2. Distribution of cTnI positive and negative values among the two groups

\begin{tabular}{|c|c|c|c|c|}
\hline & & \multicolumn{2}{|c|}{ CTnI $($ cutoff value $=0.0135 \mathrm{ng} / \mathrm{ml})$} & \multirow[b]{2}{*}{$P$ value } \\
\hline & & Positive & Negative & \\
\hline \multirow[t]{2}{*}{ Group } & CHD & $18(36.0 \%)$ & $7(14.0 \%)$ & \multirow{2}{*}{$<0.001 *$} \\
\hline & Normal & $2(4.0 \%)$ & $23(46.0 \%)$ & \\
\hline
\end{tabular}

* Statistically significant at $\mathrm{p}<0.05$, Fisher's Exact Test

This table shows the distribution of cTnI positive and negative values (at cutoff value $0.0135 \mathrm{ng} / \mathrm{ml}$ ) among the diseased and control group. Sensitivity of the test was $72 \%$, specificity of the test was $92 \%$, positive predictive value was $90 \%$ and negative predictive value was $76.7 \%$.

Table 3. Comparison of cTnI level in different classes of heart function according to Ross's classification ${ }^{\mathbf{( 2 0 )}}$.

\begin{tabular}{|l|c|c|c|}
\hline \multicolumn{1}{|c|}{ Heart failure } & Mean \pm Std. Deviation & Range & \\
\cline { 1 - 2 } No HF $(\mathrm{n}=4)$ & $0.30 \pm 0.33 \mathrm{ng} / \mathrm{ml}$ & $0.01-0.63$ & \multirow{2}{*}{ P value } \\
\cline { 1 - 2 } Mild HF $(\mathrm{n}=9)$ & $0.40 \pm 0.51 \mathrm{ng} / \mathrm{ml}$ & $0.01-1.32$ & $0.04^{*}$ \\
\cline { 1 - 2 } Moderate HF $(\mathrm{n}=10)$ & $0.73 \pm 0.41 \mathrm{ng} / \mathrm{ml}$ & $0.01-1.27$ & $0.99-1.09$ \\
\cline { 1 - 2 } Severe HF $(\mathrm{n}=2)$ & $1.03 \pm 0.07 \mathrm{ng} / \mathrm{ml}$ & \\
\hline
\end{tabular}

* Statistically significant at $\mathrm{p}<0.05$, Mann-Whitney U test 
This table shows comparison of cTnI level in different classes of heart function. cTnI level is affected by the grade of heart failure being highest in patients with severe HF and lowest in patients with no HF. $(\mathrm{P}$ value $=0.04)$

Table 4. Multiple linear regression for factors affecting cTnI level.

\begin{tabular}{|c|c|c|c|c|c|c|c|}
\hline \multirow[b]{2}{*}{ Model } & \multicolumn{2}{|c|}{$\begin{array}{l}\text { Unstandardized } \\
\text { Coefficients }\end{array}$} & \multirow{2}{*}{\begin{tabular}{|l}
$\begin{array}{l}\text { Standardized } \\
\text { Coefficients }\end{array}$ \\
Beta
\end{tabular}} & \multirow[b]{2}{*}{$\mathrm{T}$} & \multirow[b]{2}{*}{$P$ value } & \multicolumn{2}{|c|}{$95 \%$ Confidence Interval for $\beta$} \\
\hline & $B$ & Std. Error & & & & Lower Bound & Upper Bound \\
\hline (Constant) & 0.455 & 0.260 & & 1.751 & 0.087 & -0.068 & 0.978 \\
\hline Length & -0.094 & 0.039 & -0.284 & -2.418 & 0.020 & -0.172 & -0.016 \\
\hline Age in months & -0.062 & 0.023 & -0.254 & -2.754 & 0.008 & -0.108 & -0.017 \\
\hline $\mathrm{HF}$ & 0.252 & 0.054 & 0.547 & 4.706 & $<0.001$ & 0.144 & 0.360 \\
\hline
\end{tabular}

This table show multiple linear regression for factors affecting cTnI level. Linear regression analysis was done for predictors of CTnI. Factors entered into the model were heart failure, age, weight, height and antifailure treatment. According to the regression analysis model heart failure, age and length were found as predictors for $\mathrm{cTnI}$ positivity where heart failure showed the highest effect on $\mathrm{cTnI}(=0.547, \mathrm{p}$ value $<0.001)$ followed by length $(\beta=-$ 0.284 , $p$ value $=0.020)$ then age $(\beta=-0.254$, $p$ value $=0.008)$.

\section{$\underline{\underline{\text { Discussion }}}$}

Congenital heart diseases are the most common congenital anomalies, approximately $73 \%$ of infants with CHD are diagnosed before discharge from hospital after birth and $27 \%$ have late diagnosis after discharge with median age of detection 88 days ${ }^{(\mathbf{8 , 2 1})}$. Late detection of congenital heart diseases leads to 52\% more hospital admissions, 18\% more hospitalized days, 35\% higher inpatient costs and $1.8 \%$ potentially preventable deaths ${ }^{(\mathbf{2 1})}$.

A highly sensitive cTnI assay has been developed to detect very low levels of cTnI even trace leakages from the unbound cytosolic pool. Such low levels of cTnI in serum might reflect early myocardial cell death as well as reversible injury. Thus, the cTnI assay is a very useful tool for detecting subclinical heart diseases at the initial presentation ${ }^{(22)}$. 
In this study we evaluate new diagnostic modality to help early diagnosis and screening of CHD, cardiac troponin I represents an excellent choice as it is an easy test that can be done wherever, needs neither special centers nor skilled cardiologist.

We studied 50 neonates and infant, 25(50\%) healthy newborns and infants, 14(28\%) newborns and infants with simple shunts (ASD, VSD, PDA or combinations of these lesions) and $11(22 \%)$ newborns and infants with combined defects (others). Males represented $40 \%$ while females $60 \%$ in both groups. The mean age of the control group and diseased group which was 3.3 and 3.2 months respectively. Also the mean age of the group with simple shunts and the group with combined defects was 3.1 and 3.2 months respectively.

In the present work, the mean value of cardiac troponin I (cTnI) was higher in the diseased group compared to the control group, and is higher in patients with complex defects compared to patients with simple shunts. which is in agreement with the cited study of Sugimoto et al. (2011) ${ }^{(17)}$ who studied 350 healthy children, 30 children with ASD and 32 children with VSD and was the first to show that cTnI levels are higher in children with CHD than control group and that cTnI level in children with VSD was higher than its level in children with ASD.

Also Uner et al. (2014) ${ }^{(14)}$ studied 50 children with acyanotic CHD, 16 children with cyanotic CHD and 38 healthy children as a control group and reported that cTnI was found to be statistically significantly higher in the patient group than the control group, in another literature published by Eerola et al. (2013) in which they studied 78 children with CHD with volume overload, 60 children with CHD with pressure overload and 74 healthy controls, cTnI was measured at baseline prior to treatment and 6 months after treatment. They reported that $\mathrm{cTnI}$ release is more frequently associated with pressure overload than volume overload and resolves after treatment in most children.

This can be explained by what was previously published by Galderisi (2007) ${ }^{\text {(23) }}$ who reported that both ventricular hypertrophy and myocardial stretching can inhibit myocardial perfusion and that an increase in pressure inside the cardiac walls due to stretching can disturb the coronary microcirculation and this is what happen in patients with CHD with volume and pressure overload. Also Petersen et al. (2007) ${ }^{(24)}$ reported that ventricular hypertrophy lead to reduced myocardial 
perfusion reserve that was in proportion to the magnitude of hypertrophy.

To add a further depth to the findings of the current study we use ROC curve analysis to define the diagnostic performance of cTnI as a marker of CHD. We were interested in proposing a cut-off value of cTnI that could be used as a predictor of the presence of CHD. The ROC curve analysis showed that area under curve for cTnI was 0.89 . The highest diagnostic accuracy was achieved with a chosen cut-off for cTnI of $0.0135 \mathrm{ng} / \mathrm{ml}$ (sensitivity of $72 \%$, specificity of 92\%). In another literature previously published by Sugimoto et al. (2011) ${ }^{(17)}$ who studied 350 healthy children as a control group and 62 children with CHD, they reported that the $99^{\text {th }}$ percentile of $\mathrm{cTnI}$ level in the healthy group was 0.014 $\mathrm{ng} / \mathrm{ml}$.

In our study, it was found that at cutoff value of $0.0135 \mathrm{ng} / \mathrm{ml}$, cTnI was positive in 18 children in the diseased group $(n=25)$ and in 2 neonates in the control group $(\mathrm{n}=25)$, with sensitivity about $72 \%$ and specificity about $92 \%$. Uner et al. (2014) ${ }^{(14)}$ reported that of the studied 66 children with CHD there was 34 children with cTnI positive, with sensitivity of about $52 \%$. The higher sensitivity in our study is explained by the younger age of the children in our study (0-6 months) than those in their study ( 3 months- 16 years).

Also Eerola et al. (2014) ${ }^{(19)}$ reported that sensitivity of the test was about $50 \%$, the higher sensitivity in our study is explained by the fact that their study involves only one type of CHD (hypoplastic left heart syndrome) while our study involves several types of CHD either simple shunts and complex defects.

In the current study there was 2 neonates in the control group with cTnI positive (cut off value $=0.0135 \mathrm{ng} / \mathrm{ml}$ ), these 2 neonates aged 2 days and 5 days. They were normal without any CHD confirmed by echocardiography. And this finding is in agreement with the results found by Sugimoto et al. $(2011){ }^{(17)}$ who reported that there was a relationship between the cTnI level and age in the healthy group and that neonates show higher levels of cTnI, also Eerola et al. (2014) ${ }^{(\mathbf{1 9})}$ reported that among the control group enrolled in the study there was one neonate showing cTnI positive. In another literature Eerola et al. (2013) ${ }^{(18)}$ found that there was one neonate with cTnI positive in the healthy control group. 
This can be explained by what was published by Almeida et al. (2011) who studied 225 full term neonates with Apgar score more than 8 at $1 \mathrm{~min}$, they found that $\mathrm{cTnI}$ increases from $0.004 \mathrm{ng} / \mathrm{ml}$ to $0.058 \mathrm{ng} / \mathrm{ml}$ by the age of 3 days falling to $0.030 \mathrm{ng} / \mathrm{ml}$ by 10 days and this due to the early transition from fetal to neonatal circulation with increased systemic pressure and decreased pulmonary pressure which induced programmed myocyte cell death that plays an important role in determination of the number and distribution of ventricular and interventricular muscle cells.

In the present work, it was found that cTnI level is affected by the grade of heart failure. In patients with no HF the mean value of cTnI level was $0.3 \pm 0.33$ $\mathrm{ng} / \mathrm{ml}$, in patients with mild $\mathrm{HF}$ it was $0.4 \pm 0.51 \mathrm{ng} / \mathrm{ml}$, in patients with moderate $\mathrm{HF}$ it was $0.73 \pm 0.41 \mathrm{ng} / \mathrm{ml}$, and in patients with severe $\mathrm{HF}$ it was $1.03 \pm 0.07$ $\mathrm{ng} / \mathrm{ml}$. Linear regression analysis for factors affecting $\mathrm{cTnI}$ revealed significant positive correlation between $\mathrm{cTnI}$ and heart failure. This is consistent with the results found by Zhou et al. (2014) ${ }^{(13)}$ who studied 22 children with CHD and heart failure, 25 children with CHD and 25 healthy children. They reported that cTnI level and rate of positivity was significantly higher in patients with CHD and heart failure than those with CHD without heart failure.

In the current study, linear regression analysis for factors affecting cTnI revealed significant negative correlation between cTnI level and age of patient. This is in agreement with the results reported by Eerola et al. (2013) ${ }^{\text {(18) }}$ who found that the children with positive cTnI were significantly younger than those with negative cTnI.

In addition, linear regression analysis revealed significant negative correlation between cTnI level and length of patient. The degree of length affection in the patient with CHD is affected by the type of the CHD being larger in the complex $\mathrm{CHD}^{(26)}$. And as we mentioned above the cTnI level is affected by type of CHD being higher in patients with complex defects.

Studies on cTnI and other biomarkers of CHD are limited especially in developing countries, however some studies had developed in different target population, as in the study done by the Egyptian authors Hafez et al. (2015) ${ }^{(27)}$ who studied 40 children (1 month to 12 years) with acyanotic CHD, 40 children with cyanotic CHD and 40 healthy children. They reported that cTnI was significantly higher in diseased group compared to control group and that the sensitivity of the test was $80 \%$. 
Nassef et al. (2014) ${ }^{(28)}$ studied 60 children with acyanotic CHD (aged 1-4 years), 60 children with cyanotic CHD and 30 healthy children, they found that TNF- $\alpha$, IL-6, CRP, troponin T, CK-MB is significantly higher in patients with CHD than in control group.

There were a number of limitations to our study. First, the reference value of cTnI in the neonatal period is higher than infancy and childhood, with lack of studies about this. More studies is needed to define the reference values of cTnI throughout the neonatal period.

Second, the unavailability of pediatric cardiac catheterization at our hospital prevents us from assessing the effect of specific hemodynamics on cTnI level

Finally, the lack of financial resources prevents us from studying more than one biomarker and comparing their results to assess the effect of their individual or simultaneous use.

\section{Conclusion}

In conclusion, we have shown that serum cTnI level was found to have a statistically significant association with congenital heart disease, being higher in complex defects than simple shunts. Sensitivity of the test was $72 \%$, specificity of the test was $92 \%$. cTnI level was affected by the grade of heart failure being highest in patients with severe HF and lowest in patients with no HF with statistically significant difference. Also cTnI level showed statistically significant negative correlation with age. The use of cTnI may provide us with additional tool for earlier detection of CHD. 


\section{$\underline{\underline{\text { References }}}$}

1. Van der Linde D, Konings EE, Slager MA, et al. Birth prevalence of congenital heart disease worldwide: a systematic review and metaanalysis. J Am Coll Cardiol 2011; 58(21), 2241-2247.

2. Torky H, Anwar A, Elebrashy A, et al. Incidence of antenatal moderate and severe congenital cardiac anomalies in Cairo (a multi-center retrospective study). Pregnancy Hypertens 2016; 6(2), 126-129.

3. Marelli AJ, Ionescu-Ittu R, Mackie AS, et al. Lifetime prevalence of congenital heart disease in the general population from 2000 to 2010 . Circulation 2014; 130(9), 749-756.

4. Khairy P, Ionescu-Ittu R, Mackie AS, el al. Changing mortality in congenital heart disease. J Am Coll Cardiol 2010; 56(14), 1149-1157.

5. Ooki S. Maternal age and birth defects after the use of assisted reproductive technology in Japan, 2004-2010. Int J Womens Health 2013; 5, 65-77.

6. Madsen NL, Schwartz SM, Lewin MB, et al. Prepregnancy body mass index and congenital heart defects among offspring: a population-based study. Congenit Heart Dis 2013; 8(2), 131-41.

7. Feng Y, Yu D, Yang L, et al. Maternal lifestyle factors in pregnancy and congenital heart defects in offspring: review of the current evidence [online]. Ital J Pediatr 2014; 40, 85. Available from:

http://www.ijponline.net/content/40/1/85 [Accessed 23 Aug 2015].

8. Meberg A. congenital heart defects through 30 years [online]. Ojped 2012; 2, 219-227. Available from: http://file.scirp.org/Html/22931.html [Accessed 15 Aug 2015].

9. Abid D, Elloumi A, Abid L, et al. Congenital heart disease in 37,294 births in Tunisia: birth prevalence and mortality rate. Cardiol Young 2014; 24(5), 866-871.

10.Eckersley L, Sadler L, Parry E, et al. Timing of diagnosis affects mortality in critical congenital heart disease [online]. Arch Dis Child 2015; article ID: 307691. Available from: http://www.ncbi.nlm.nih.gov/pubmed/26130379 [Accessed 10 Aug 2015].

11. Sugimoto M, Kuwata S, Kurishima C, et al. Cardiac biomarkers in children with congenital heart disease. World J Pediatr 2015; 11(4), 309315 .

12.Tarkowska A, Furmaga-Jablonska W. The evaluation of diagnostic role of cardiac troponin $\mathrm{T}(\mathrm{cTnT})$ in newborns with heart defects [online]. ScientificWorldJournal 2012; article ID 682538. Available from: http://www.ncbi.nlm.nih.gov/pmc/articles/PMC3324289/ [Accessed 25 April 2015].

13.Zhou FJ, Zhou CY, Tian YJ, et al. Diagnostic value of analysis of HFABP, NT-proBNP, and cTnI in heart function in children with congenital 
heart disease and pneumonia. Eur Rev Med Pharmacol Sci 2014; 18(10), 1513-1516.

14.Uner A, Dogan M, Ay M, et al. The evaluation of serum N-terminal prohormone brain-type natriuretic peptide, troponin-I, and high-sensitivity $\mathrm{C}$-reactive protein levels in children with congenital heart disease. Hum Exp Toxicol 2014; 33(11), 1158-1166.

15. Voicu S, Sideris G, Deye N, et al. Role of cardiac troponin in the diagnosis of acute myocardial infarction in comatose patients resuscitated from outof-hospital cardiac arrest. Resuscitation 2012; 83(4), 452-458.

16.Liebetrau C, Weber M, Tzikas S, et al. Identification of acute myocardial infarction in patients with atrial fibrillation and chest pain with a contemporary sensitive troponin I assay. BMC Med 2015; 13, 169.

17.Sugimoto M, Ota K, Kajihama A, et al. Volume overload and pressure overload due to left to right shunt induced myocardial injury. Evaluation using a highly sensitive cardiac Troponin-I assay in children with congenital heart disease. Circ J 2011; 75(9), 2213-2219.

18.Eerola A, Jokinen EO, Savukoski TI, et al. Cardiac troponin I in congenital heart defects with pressure or volume overload. Scand Cardiovasc J 2013; 47(3), 154-159.

19.Eerola A, Poutanen T, Savukoski T, et al. Cardiac troponin I, cardiac troponin-specific autoantibodies and natriuretic peptides in children with hypoplastic left heart syndrome. Interact Cardiovasc Thorac Surg 2014; $18(1), 80-85$.

20.Ross RD. The Ross classification for heart failure in children after 25 years: a review and an age-stratified revision. Pediatr Cardiol 2012; 33(8), 1295-1300.

21.Peterson C, Dawson A, Grosse SD, et al. Hospitalizations, costs, and mortality among infants with critical congenital heart disease: how important is timely detection. Birth Defects Res A Clin Mol Teratol 2013; 97(10), 664-672.

22.Melanson SE, Morrow DA, Jarolim P. Earlier detection of myocardial injury in a preliminary evaluation using a new troponin I assay with improved sensitivity. Am J Clin Pathol 2007; 128(2), 282-286.

23. Galderisi M. Epicardial coronary vessels and coronary microcirculation in pressure overload hypertrophy: a complex interaction. Am J Hypertens 2007; 20(3), 285-286.

24.Petersen SE, Jerosch-Herold M, Hudsmith LE et al. Evidence for microvascular dysfunction in hypertrophic cardiomyopathy: new insights from multiparametric magnetic resonance imaging. Circulation 2007; 115(18), 2418-2425. 
25.Almeida CM, Carrapato MR, Pinto F. Biochemical markers of neonatal myocardial dysfunction. J Matern Fetal Neonatal Med 2011; 24(4), 568573.

26.Daymont C, Neal A, Prosnitz A, et al. Growth in children with congenital heart disease. Pediatrics 2013; 131(1), e236-242.

27.Hafez MO, Morsy SM, Mahfoz RA, et al. Myocardial Injury in Children with Unoperated Congenital Heart Diseases[online]. Cardiol Res Pract 2015; article ID: 104818. Available:

http://www.ncbi.nlm.nih.gov/pmc/articles/PMC4243331 [accessed 13 aug 2016]

28.Nassef YE, Hamed MA, Aly HF (2014) Inflammatory cytokines, apoptotic, tissue injury and remodeling biomarkers in children with congenital heart disease. Indian J Clin Biochem 2014; 29(2), 145-149. 
Medicine Updates

Faculty of medicine

April 2020,volume 1, issue 1 https://muj.journals.ekb.eg

dean@med.psu.edu.eg

vice_dean_postgraduate@med.psu.edu.eg

DOI: $10.21608 / \mathrm{muj} .2020 .25068 .1002$

ISSN : 2682-2741

Submitted: $3 / 2 / 2020$

Accepted : 12/3/2020

Pages:55-67

\title{
Is urinary kim-1 a better biomarker than its serum value in diagnosis of :Acute Kidney Injury disease
}

Shadwa mohamed Ali El-Esawy B.Sc. in Biochemistry/ Chemistery Faculty of .science, Port Said University

Rasha EL-Sherif Hassan assistant professor of Biochemistry. Faculty of Science .Ain Shams University

Asmaa Mohamed Nabiel Eessa Lecturer of Geriatric Medicine and Gerontology .Faculty of Medicine Port Said University

Prof. Dr. Magdy Mahmoud Mohamed Professor of Biochemistry Faculty of Science Ain Shams University

\begin{abstract}
$\underline{\text { Abstract: }}$
Background: Urinary Kidney Injury Molecule 1 (KIM-1) is a proximal tubular injury biomarker for early detection of acute kidney injury (AKI(

Aim of the study: To study the accuracy of Serum (KIM-1) test and Urinary kim1 as an earlier biomarkers rather than serum creatinine (S.Cr) in early diagnosis of (AKI).

Methods: a prospective observational case control study was carried out on 10 adult subjects as a control group and 45 non diabetic subjects with normal serum creatinine but at risk of developing acute kidney injury recruited from intensive care unit in Port Said National hospital with normal serum creatinine and at risk of developing acute kidney injury. Age of all participants ranged from 47 years to 76 years old. Blood
\end{abstract}


and urin samples were collected to measure and compare serum creatinine ,urea, albumin/creatinin ratio ,uric acid and estimated glomular filtration rate, serum (KIM-1) and Urinary kim-1.

Results : Urinary KIM-1 represents an early marker for predicting AKI and therefore measurements of urinary KIM-1 by ELISA increased obviously by many folds in AKI patients than its average number of healthy patients at different times (baseline, 24hr, 48hr, $72 \mathrm{hr}$ and $96 \mathrm{hr}$ by $2,4,7,8$, and 16 times respectively more than normal subject values). While its increase in serum were high $(1.5,3.4,5.5$ and 6.5 respectively at same period of experimental time compared to normal subjects

Conclusion: the study demonstrates that urinary and serum kim-1 are reliable markers for early detection \& diagnosis of AKI. Moreover, urinary KIM-1 is more sensitive than serum KIM-1 for early detection of AKI.

\section{Keywords}

Acute kidney injury. Urine Kidney injury molecule-1. Serum Kidney injury molecule-1

\section{Abbreviations}

AKI Acute Kidney Injury

AKIN Acute Kidney Injury Network

ARF Acute Renal Failure

BUN Blood Urea Nitrogen

CKD Chronic Kidney Disease

ESRD End Stage Renal Disease

GFR Glomerular Filtration Rate

ICU Intensive Care Unit

KIM-1 Kidney Injury Molecule-1

s Cr Serum creatinine

s/uKIM-1 Serum/urine Kidney Injury Molecule-1 55 
ROC Receiver operating characteristics

\section{Introduction}

Acute Kidney Injury Network (AKIN) criteria consider serum creatinine (SCr) as the gold standard of kidney injury . Unfortunately, creatinine is an unreliable indicator during acute changes in kidney function (Dennen et al., 2007). (SCr) levels vary widely with age, gender, muscle mass, muscle metabolism, medication and hydration status. Its concentrations may not change until a substantial portion of kidney function has already been lost, due to a large renal reserve (Hirschberg et al., 1999).

Kidney injury molecule-1 (KIM-1), a recently discovered transmembrane tubular protein, is markedly induced in renal injury including acute kidney injury (AKI) and chronic kidney disease (CKD) (Shao et al., 2014). In renal patients, KIM-1 is up-regulated in a variety of conditions including ischemia, nephrotoxic drugs, $\mathrm{CKD}$, and acute/chronic renal transplant dysfunction. There are many studies shows that KIM-1 is a sensitive and specific marker of kidney injury as well as a predictor of prognosis (Rees et al., 2008). KIM-1 is considered as an ideal biomarker for kidney injury because it is not expressed in normal kidney but specifically expressed in injured proximal tubular cells, and such an expression can persist until the damaged cells have completely recovered. Moreover, the rapid and integrated cleavage of its ectodomain into the lumens of kidney tubules can make it detectable in urine(Chaturvedi et al.,2009).Urinary KIM-1 level is closely related to tissue KIM-1 and correlates with the severity of renal damage, so measurement of urinary KIM-1 is likely to be a noninvasive and sensitive method for the evaluation of kidney injury and even for monitoring of the response of treatment (Bonventre,2009)

\section{Materials and Methods}

Design : prospective observational study

Participants : the study includes 55 participants .10 participants were considered as a control group which was compared with 45 cases in ICU for 5 -7 days .Blood and urine samples were collected from both control group and cases in ICU who were at high risk of AKI .They were selected by normal creatinine level in non diabetic patients and hospitalized for 5-7 days and had causes including shock, sepsis, contrast used in coronary angiography and those with chronic use of non steroidal drugs . 55 
According to these factors, patients were classified into three groups as follows:

Group I- Pre-renal acute kidney injury patients includes patients who were suffering of dehydration or bleeding, were 15 cases $(27.3 \%)$.

Group II- Renal acute kidney injury patients, includes patients who were suffering of contrast induced nephropathy or drug induced nephropathy, Were 15 cases $(27.35 \%)$.

Group III- Post renal acute kidney injury includes patients who were suffering of prostatic hyperplasia or uretric stone causing hydronephrosis, Were 15 cases $(27.3 \%)$.

The total 55 subject were divided by gender as follow 26 males (47\%) And 29 females $(53 \%)$, age ranged from 47 years to 76 years, weight ranged from 55 kilograms to 110 kilograms, length ranged from 160 to 189 Meter, blood pressure ranged from $90 / 50$ to 200/110. Blood and urine samples were collected to measure and compare serum creatinine, urea, albumin/creatinin ratio, uric acid and estimated glomular filtration rate with serum (KIM-1) and Urinary kim-1 for 5-7 days.

\section{Methods}

\section{Serological analysis of kidney functions}

Serum creatinine, albumin, Albumin/creatinine ratio (ACR), urea, uric acid and urine microalbuminuria were determined by using an enzymatic assay (Creatinine Plus; Roche Diagnostics, Branchburg, NJ, USA) on a cobas 8000 analyzer (Roche Diagnostics) according to the manufacture illustration. In additional to measurement of urine creatinine for creatinine clearance and determine estimate glomerular filtration rate (eGFR). Glomerular filtration rate was calculated according to the Schwartz formula. Urine supernatants and serum samples were frozen until analysis at $-70^{\circ} \mathrm{C}$. Commercially available enzymelinked immunosorbent assay kit (ELISA assay kit) USCN Life Science, Hankou, Wuhan, China was used to determine s/uKIM-1 and was expressed in nanograms per milligram creatinine ( $\mathrm{ng} / \mathrm{mg} \mathrm{cr}$.).

\section{Statistical analysis}

SSPS 22 package program (IBM Corp., Armonk, NY, USA) was used for statistical analyses. Evaluated data were presented as mean \pm SD and percentage values. Chi-square test was used to evaluate the categorized variables. Spearman analysis was used for evaluation of the correlation of the variables between groups. $p$ value $<0.0555$ 
was taken as the statistical significance threshold level. The areas under the ROC curve (AUCs) with 95\% confidence intervals (95\% CI) were calculated. Also, for each timeframe, the optimal cutoff value based on the Youden index was calculated with corresponding sensitivity and specificity. Using those cutoff values, sensitivity and specificity of biomarkers for predicting AKI. Also who developed AKI later within the study period ( $<48$ hours post-admission) after being considered AKI-free upon admission. Of these patients, the timing and absolute values of maximum biomarker levels in urine samples preceding AKI were compared with biomarker levels in the first urine and serum samples of controls. Oral and written informed consent was obtained from all subjects before the start of the study. The study was approved by the Portsaid University Ethics Committee.

\section{$\underline{\text { Results }}$}

A total of 45 patients with AKI were studied. There were 21 (46.67\%) male patients, and there were $24(53.33 \%)$ female patients. The ages of patients ranged from 47 to 76 years.

\section{Biochemical investigations}

Table (1). Biochemical parameters of controlled and AKI patients

\begin{tabular}{|c|c|c|c|c|c|}
\hline parameters & Baseline & $24 \mathrm{hr}$ & $48 \mathrm{hr}$ & $72 \mathrm{hr}$ & $96 \mathrm{hr}$ \\
\hline $\begin{array}{l}\text { uCr mean } \\
\text { mg/dl } \pm \text { SD } \\
\text { Non-AKI } \\
\text { control }(\mathrm{n}=10) \\
\text { AKI patients } \\
(\mathrm{n}-45) \\
\mathrm{P} \text { value < }\end{array}$ & $\begin{array}{l}631.0 \pm 87.0 \\
600.9 \pm 17.15 \\
\mathrm{NS}\end{array}$ & $\begin{array}{l}611.0 \pm 67.0 \\
430.1 \pm 32.52 \\
0.001\end{array}$ & $\begin{array}{l}639.0 \pm 72.0 \\
328.7 \pm 18.80 \\
0.001\end{array}$ & $\begin{array}{l}628.0 \pm 65.0 \\
168.1 \pm 20.97 \\
0.001\end{array}$ & $\begin{array}{l}624.0 \pm 59.0 \\
76.29 \pm 12.37 \\
0.001\end{array}$ \\
\hline $\begin{array}{l}\text { eGFR } \\
\mathrm{ml} / \mathrm{min} / 1.73 \mathrm{~m} 2 \\
\text { mean } \pm \text { SD } \\
\text { Non-AKI } \\
\text { control } 9 \mathrm{~N}-10) \\
\text { AKI patients } \\
(\mathrm{N}=45) \\
\mathrm{P} \text { value }<\end{array}$ & $\begin{array}{l}127.0 \pm 29.40 \\
152.0 \pm 7.16 \\
\text { NS }\end{array}$ & $\begin{array}{l}136.0 \pm 25.30 \\
122.4 \pm 5.34 \\
\text { NS }\end{array}$ & $\begin{array}{l}141.0 \pm 32.70 \\
97.64 \pm 13.41 \\
0.001\end{array}$ & $\begin{array}{l}147.0 \pm 86.20 \\
52.42 \pm 11.0 \\
0.001\end{array}$ & $\begin{array}{l}134.0 \pm 22.55 \\
21.78 \pm 5.47 \\
0.001\end{array}$ \\
\hline $\begin{array}{l}\text { u-kim-1 ng/mg } \\
\text { uCr } \\
\text { mean ng/ml } \\
\pm \text { SD } \\
\text { Non-AKI } \\
\text { control }(\mathrm{n}=10) \\
\text { AKI patients } \\
(\mathrm{n}=45)\end{array}$ & $\begin{array}{l}18.80 \pm 3.91 \\
34.07 \pm 5.12 \\
0.001\end{array}$ & $\begin{array}{l}17.60 \pm 3.91 \\
77.32 \pm 6.94 \\
0.001\end{array}$ & $\begin{array}{l}19.57 \pm 3.91 \\
128.3 \pm 8.97 \\
0.001\end{array}$ & $\begin{array}{l}20.10 \pm 3.91 \\
194.1 \pm 13.93 \\
0.001\end{array}$ & $\begin{array}{l}18.34 \pm 3.91 \\
287.8 \pm 29.33 \\
0.001\end{array}$ \\
\hline
\end{tabular}




\begin{tabular}{|c|c|c|c|c|c|}
\hline $\mathrm{P}$ value $<$ & & & & & \\
\hline parameters & Baseline & $24 \mathrm{hr}$ & $48 \mathrm{hr}$ & $72 \mathrm{hr}$ & $96 \mathrm{hr}$ \\
\hline $\begin{array}{l}\text { uCr mean } \\
\mathrm{mg} / \mathrm{dl} \pm \mathrm{SD} \\
\text { Non-AKI } \\
\text { control }(\mathrm{n}=10) \\
\text { AKI patients } \\
(\mathrm{n}-45) \\
\mathrm{P} \text { value < }\end{array}$ & $\begin{array}{l}631.0 \pm 87.0 \\
600.9 \pm 17.15 \\
N S\end{array}$ & $\begin{array}{l}611.0 \pm 67.0 \\
430.1 \pm 32.52 \\
0.001\end{array}$ & $\begin{array}{l}639.0 \pm 72.0 \\
328.7 \pm 18.80 \\
0.001\end{array}$ & $\begin{array}{l}628.0 \pm 65.0 \\
168.1 \pm 20.97 \\
0.001\end{array}$ & $\begin{array}{l}624.0 \pm 59.0 \\
76.29 \pm 12.37 \\
0.001\end{array}$ \\
\hline $\begin{array}{l}\text { eGFR } \\
\mathrm{ml} / \mathrm{min} / 1.73 \mathrm{~m} 2 \\
\text { mean } \pm \text { SD } \\
\text { Non-AKI } \\
\text { control 9N-10) } \\
\text { AKI patients } \\
(\mathrm{N}=45) \\
\mathrm{P} \text { value < }\end{array}$ & $\begin{array}{l}127.0 \pm 29.40 \\
152.0 \pm 7.16 \\
N S\end{array}$ & $\begin{array}{l}136.0 \pm 25.30 \\
122.4 \pm 5.34 \\
\text { NS }\end{array}$ & $\begin{array}{l}141.0 \pm 32.70 \\
97.64 \pm 13.41 \\
0.001\end{array}$ & $\begin{array}{l}147.0 \pm 86.20 \\
52.42 \pm 11.0 \\
0.001\end{array}$ & $\begin{array}{l}134.0 \pm 22.55 \\
21.78 \pm 5.47 \\
0.001\end{array}$ \\
\hline $\begin{array}{l}\text { u-kim-1 ng/mg } \\
\text { uCr } \\
\text { mean ng/ml } \\
\pm \text { SD } \\
\text { Non-AKI } \\
\text { control }(\mathrm{n}=10) \\
\text { AKI patients } \\
(\mathrm{n}=45) \\
\mathrm{P} \text { value < }\end{array}$ & $\begin{array}{l}18.80 \pm 3.91 \\
34.07 \pm 5.12 \\
0.001\end{array}$ & $\begin{array}{l}17.60 \pm 3.91 \\
77.32 \pm 6.94 \\
0.001\end{array}$ & $\begin{array}{l}19.57 \pm 3.91 \\
128.3 \pm 8.97 \\
0.001\end{array}$ & $\begin{array}{l}20.10 \pm 3.91 \\
194.1 \pm 13.93 \\
0.001\end{array}$ & $\begin{array}{l}18.34 \pm 3.91 \\
287.8 \pm 29.33 \\
0.001\end{array}$ \\
\hline parameters & Baseline & $24 \mathrm{hr}$ & $48 \mathrm{hr}$ & $72 \mathrm{hr}$ & 96hr \\
\hline $\begin{array}{l}\text { uCr mean } \\
\mathrm{mg} / \mathrm{dl} \pm \mathrm{SD} \\
\text { Non-AKI } \\
\text { control }(\mathrm{n}=10) \\
\text { AKI patients } \\
(\mathrm{n}-45) \\
\mathrm{P} \text { value < }\end{array}$ & $\begin{array}{l}631.0 \pm 87.0 \\
600.9 \pm 17.15 \\
\mathrm{NS}\end{array}$ & $\begin{array}{l}611.0 \pm 67.0 \\
430.1 \pm 32.52 \\
0.001\end{array}$ & $\begin{array}{l}639.0 \pm 72.0 \\
328.7 \pm 18.80 \\
0.001\end{array}$ & $\begin{array}{l}628.0 \pm 65.0 \\
168.1 \pm 20.97 \\
0.001\end{array}$ & $\begin{array}{l}624.0 \pm 59.0 \\
76.29 \pm 12.37 \\
0.001\end{array}$ \\
\hline $\begin{array}{l}\text { eGFR } \\
\mathrm{ml} / \mathrm{min} / 1.73 \mathrm{~m} 2 \\
\text { mean } \pm \mathrm{SD} \\
\text { Non-AKI } \\
\text { control } 9 \mathrm{~N}-10) \\
\text { AKI patients } \\
(\mathrm{N}=45) \\
\mathrm{P} \text { value }<\end{array}$ & $\begin{array}{l}127.0 \pm 29.40 \\
152.0 \pm 7.16 \\
\text { NS }\end{array}$ & $\begin{array}{l}136.0 \pm 25.30 \\
122.4 \pm 5.34 \\
\text { NS }\end{array}$ & $\begin{array}{l}141.0 \pm 32.70 \\
97.64 \pm 13.41 \\
0.001\end{array}$ & $\begin{array}{l}147.0 \pm 86.20 \\
52.42 \pm 11.0 \\
0.001\end{array}$ & $\begin{array}{l}134.0 \pm 22.55 \\
21.78 \pm 5.47 \\
0.001\end{array}$ \\
\hline
\end{tabular}

urine creatinine, GFR, and urine KIM-1 in addition to serum creatinine, urea, uric acid, albumin, microalbuminurea and KIM-1. All values were represented in (Table 1). 
One of the most promising biochemical parameters for predicting AKI cases at early stage as determined by serum and urine KIM-1 levels measured by ELISA technique which, represented a highly significant increase starting from baseline, and continuously elevated after $24 \mathrm{~h}, 48 \mathrm{~h}, 72 \mathrm{~h}$ and $96 \mathrm{~h}(\mathrm{p}<0.001)$ of icu admission.

It is surprisingly to note that most of other biochemical parameters as serum, urea, uric acid, albumin/creatinine ratio (ACR), and urine creatinine levels showed no significant difference at $0 \mathrm{hr}$ of ICU admission while showed a highly significant increase at $24 \mathrm{~h}, 48 \mathrm{~h}, 72 \mathrm{~h}$ and $96 \mathrm{~h}(\mathrm{p}<0.001)$ of AKI group. Meanwhile, a significant decrease in serum albumin level was detected only after passing of $24 \mathrm{hr}$ of icu admission.

On the other hand, no significant differences were observed in serum creatinine levels or estimate glomerular filtration rate (eGFR) was observed among AKI patients compared with control subjects up to $24 \mathrm{~h}$ of the admission to ICU. While AKI patients showed a marked significant increase in both parameters $(p<0.001)$ at 48,72 and 96 hours of ICU admission. 
Table (2): Correlation between different s/uKIM-1 at 0, 24, 48, 72 and $96 \mathrm{hr}$ in relation to studied parameters among AKI patients group $(n=45)$.

\begin{tabular}{|c|c|c|c|c|c|c|c|c|c|c|c|}
\hline & & \multicolumn{2}{|c|}{ Baseline } & \multicolumn{2}{|c|}{$24 \mathrm{hr}$} & \multicolumn{2}{|c|}{$48 \mathrm{hr}$} & \multicolumn{2}{|c|}{$72 \mathrm{hr}$} & \multicolumn{2}{|c|}{$96 \mathrm{hr}$} \\
\hline & & $\begin{array}{l}\text { Serum } \\
\text { KIM-1 }\end{array}$ & $\begin{array}{l}\text { Urine } \\
\text { KIM-1 }\end{array}$ & $\begin{array}{l}\text { Serum } \\
\text { KIM-1 }\end{array}$ & $\begin{array}{l}\text { Urine } \\
\text { KIM-1 }\end{array}$ & $\begin{array}{l}\text { Serum } \\
\text { KIM-1 }\end{array}$ & $\begin{array}{c}\text { Urine } \\
\text { KIM-1 }\end{array}$ & $\begin{array}{l}\text { Serum } \\
\text { KIM-1 }\end{array}$ & $\begin{array}{l}\text { Urine } \\
\text { KIM-1 }\end{array}$ & $\begin{array}{l}\text { Serum } \\
\text { KIM-1 }\end{array}$ & $\begin{array}{c}\text { Urine } \\
\text { KIM-1 }\end{array}$ \\
\hline \multirow{2}{*}{ eGFR } & $\mathbf{r}$ & 0.122 & -0.009 & -0.156 & $-0.09 \mid 1$ & -0.196 & $-0.303^{*}$ & -0.168 & 0.053 & -0.023 & $0.320^{7}$ \\
\hline & p & 0.424 & 0.953 & 0.306 & 0.551 & 0.197 & 0.043 & 0.271 & 0.729 & 0.883 & 0.032 \\
\hline \multirow{2}{*}{$\mathrm{uCr}$} & $\mathbf{r}$ & -0.150 & 0.070 & -0.213 & 0.194 & -0.010 & $\mid-0.109$ & 0.064 & 0.108 & 0.094 & 0.093 \\
\hline & p & 0.324 & 0.647 & 0.161 & 0.201 & 0.946 & 0.476 & 0.678 & 0.479 & 0.539 & 0.543 \\
\hline \multirow{2}{*}{$\mathrm{sCr}$} & $\mathbf{r}$ & 0.123 & -0.119 & 0.292 & -0.106 & 0.047 & 0.006 & -0.060 & 0.116 & -0.186 & 0.110 \\
\hline & p & 0.423 & 0.436 & 0.051 & 0.487 & 0.758 & 0.970 & 0.695 & 0.448 & 0.222 & 0.474 \\
\hline \multirow{2}{*}{ s. urea } & $r$ & 0.127 & 0.050 & 0.159 & -0.412 & -0.065 & -0.140 & -0.029 & 0.019 & -0.134 & -0.150 \\
\hline & p & 0.404 & 0.747 & 0.297 & 0.005 & 0.669 & 0.359 & 0.850 & 0.903 & 0.379 & 0.325 \\
\hline \multirow{2}{*}{ s. uric acid } & $r$ & 0.006 & 0.027 & -0.293 & $-0.470^{3}$ & $-0.320^{*}$ & 0.032 & -0.148 & -0.025 & 0.039 & -0.047 \\
\hline & p & 0.970 & 0.860 & 0.051 & 0.001 & 0.032 & 0.836 & 0.333 & 0.872 & 0.799 & 0.758 \\
\hline \multirow{2}{*}{ s.albumin } & $\mathbf{r}$ & -0.116 & 0.030 & -0.130 & 0.001 & 0.058 & 0.187 & 0.243 & -0.102 & 0.184 & -0.118 \\
\hline & p & 0.447 & 0.842 & 0.394 & 0.997 & 0.703 & 0.218 & 0.108 & 0.506 & 0.226 & 0.442 \\
\hline \multirow{2}{*}{$\mu$-albuminuria } & $\mathbf{r}$ & 0.114 & -0.148 & 0.171 & -0.005 & 0.263 & 0.021 & 0.082 & -0.059 & 0.124 & -0.239 \\
\hline & p & 0.456 & 0.332 & 0.262 & 0.976 & 0.081 & 0.893 & 0.593 & 0.701 & 0.418 & 0.114 \\
\hline \multirow{2}{*}{ ACR } & $r$ & $0.341^{*}$ & -0.134 & 0.198 & -0.076 & 0.222 & 0.071 & -0.043 & -0.063 & 0.054 & -0.048 \\
\hline & p & 0.022 & 0.379 & 0.193 & 0.621 & 0.142 & 0.644 & 0.777 & 0.681 & 0.723 & 0.756 \\
\hline
\end{tabular}

r: Pearson coefficient *: Statistically significant at $\mathrm{p} \leq 0.05$ the table shows positive correlation between serum KIM-1 level and ACR at o hr of ICU admission, followed by a reverse correlation between urine KIM-1 and both serum urea or uric acid at $48 \mathrm{hr}$ of ICU admission.

Table (3): Comparison between mean values for 3 sub-groups pre-renal, renal and post-renal according to Serum KIM-1

\begin{tabular}{|l|l|l|l|l|l|}
\hline & Baseline & $\mathbf{2 4}$ hours & $\mathbf{4 8}$ hours & $\mathbf{7 2}$ hours & 96 hours \\
\hline $\begin{array}{l}\text { Pre-renal (n = } \\
\mathbf{1 5})\end{array}$ & $23.47 \pm 3.64$ & $50.58 \pm 9.61$ & $70.54 \pm 12.49$ & $93.54 \pm 10.43$ & $115.0 \pm 12.63$ \\
\hline Renal $(\mathbf{n}=\mathbf{1 5})$ & $24.58 \pm 4.42$ & $51.56 \pm 7.85$ & $77.15 \pm 7.86$ & $97.12 \pm 7.31$ & $120.88 \pm 12.26$ \\
\hline $\begin{array}{l}\text { Post-renal }(\mathbf{n}= \\
\text { 15) }\end{array}$ & $23.21 \pm 3.34$ & $51.01 \pm 4.52$ & $68.54 \pm 7.08$ & $88.61 \pm 9.45$ & $109.29 \pm 8.41$ \\
\hline $\begin{array}{l}\text { Total AKI (n = } \\
\text { 45) }\end{array}$ & $23.75 \pm 3.78$ & $51.05 \pm 7.46$ & $72.08 \pm 9.96$ & $93.09 \pm 9.62$ & $115.06 \pm 12.0$ \\
\hline
\end{tabular}


Table (4): Comparison between mean values for 3 sub-groups pre-renal, renal and post-renal according to Urine KIM-1

\begin{tabular}{|l|l|l|l|l|l|}
\hline & Baseline & 24 hours & 48 hours & 72 hours & 96 hours \\
\hline Pre-renal $(\mathbf{n}=\mathbf{1 5})$ & $35.59 \pm 6.69$ & $81.81 \pm 7.02$ & $128.67 \pm 11.08$ & $192.11 \pm 13.33$ & $285.67 \pm 28.45$ \\
\hline Renal $(\mathbf{n}=\mathbf{1 5})$ & $33.03 \pm 3.71$ & $76.82 \pm 7.08$ & $129.05 \pm 5.90$ & $193.81 \pm 12.92$ & $277.55 \pm 29.94$ \\
\hline Post-renal $(\mathbf{n}=\mathbf{1 5})$ & $33.59 \pm 4.47$ & $73.34 \pm 3.63$ & $127.13 \pm 9.65$ & $196.30 \pm 15.99$ & $300.29 \pm 26.72$ \\
\hline Total AKI $(\mathbf{n}=45)$ & $34.07 \pm 5.12$ & $77.32 \pm 6.94$ & $128.28 \pm 8.97$ & $194.07 \pm 13.93$ & $287.84 \pm 29.33$ \\
\hline
\end{tabular}

Table (5): Sensitivity and specificity of s/u KIM-1, s. creatinine and s. urea of AKI patients $(n=45)$ at different experimental time schedule

\begin{tabular}{|c|c|c|c|c|c|c|c|c|c|c|c|c|c|c|c|c|c|c|c|c|}
\hline Time & \multicolumn{4}{|c|}{ Ohr } & \multicolumn{4}{|c|}{ 2thr } & \multicolumn{4}{|c|}{$48 \mathrm{hr}$} & \multicolumn{4}{|c|}{$72 \mathrm{hr}$} & \multicolumn{4}{|c|}{ 96hr } \\
\hline Parameter & AUC & Uू & 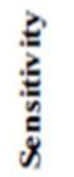 & 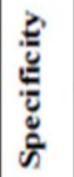 & AUC & Ü & 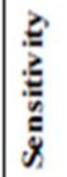 & 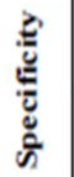 & $\mathrm{AUC}$ & U⿺ & 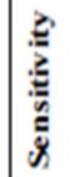 & 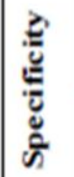 & $A U C$ & U⿺ & 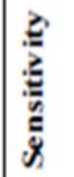 & $\begin{array}{l}\text { 岂 } \\
\text { के } \\
\text { के }\end{array}$ & AUC & U & 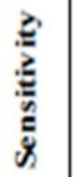 & 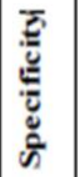 \\
\hline $\mathrm{sKIM}-\mathrm{lng} / \mathrm{ml}$ & $0.928^{\circ}$ & $>20$ & 80.0 & 100.0 & $1.000^{\circ}$ & $>20$ & 100.0 & 100.0 & $1.000^{\circ}$ & $1.000^{\circ}$ & 1.000 & $1.000^{\circ}$ & $1.000^{\circ}$ & $>20$ & 100.0 & 100.0 & $1.000^{\circ}$ & $>20$ & 100.0 & 100.0 \\
\hline $\mathrm{uKIM}-\mathrm{l} \mathrm{ng} / \mathrm{ml}$ & $0.996^{\circ}$ & $>28$ & 95.56 & 100.0 & $1.000^{\circ}$ & $>28$ & 100.0 & 100.0 & $1.000^{\circ}$ & $1.000^{\circ}$ & 1.000 & $1.000^{\circ}$ & $1.000^{\circ}$ & $>28$ & 100.0 & 100.0 & $1.000^{\circ}$ & $>28$ & 100.0 & 100.0 \\
\hline $\mathrm{s} \mathrm{Cr} \mathrm{mg} / \mathrm{dl}$ & 0.559 & $\leq 0.8$ & 66.67 & 50.0 & 0.658 & $>1$ & 31.11 & 100.0 & $0.893^{\circ}$ & $0.893^{\prime}$ & 0.893 & $0.893^{\circ}$ & $0.996^{\circ}$ & $>1$ & 95.56 & 100.0 & $1.000^{\circ}$ & $>1$ & 100.0 & 100.0 \\
\hline surea $\mathrm{mg} / \mathrm{dl}$ & 0.583 & $\leq 18$ & 84.44 & 40.0 & $0.871^{\circ}$ & $>19$ & 80.0 & 80.0 & $0.978^{\circ}$ & 0.978 & 0.978 & $0.978^{\circ}$ & $1.000^{\circ}$ & $>24$ & 100.0 & 100.0 & $1.000^{\circ}$ & $>24$ & 100.0 & 100.0 \\
\hline
\end{tabular}

AUC: Area Under a Curve *: Statistically significant at $\mathrm{p} \leq 0.05$ \#Cut off was choose according to Youden index

Sensitivity and specificity of serum and urine KIM-1 as well as kidney function parameters (serum urea and creatinine) were determined at different time of experimental schedule in order to identify which parameter more sensitive and specific at early AKI condition. It is clear to note that both specificity and sensitivity of serum and urine KIM-1 very high at $0 \mathrm{hr}(80-100 \%)$ while serum urea and creatinine were very low at $0 \mathrm{hr}(40-84 \%)$ and increase gradually to reach the maximum after $96 \mathrm{hr}$ as represented in table 3 


\section{Discussion}

Known kidney biomarkers are serum creatinine, blood urea nitrogen, urinary microalbumin, and total volume of urine may be detected after at least 24hour of kidney injury . An early detection of AKI requires more sensitive biomarkers than the current traditional methods (Bihorac et al., 2013). Diagnosis of AKI in the reversible stage, depends on the time passed to detect a significant level of biomarkers as soon as the damage has been occurred. The specificity of these biomarkers, which are produced from the damaged renal cells and its concentration, should be proportional to the extent and level of damage (Mårtensson et al., 2012). In our study, serum creatinine and eGFR were significantly affected after passing of 48hours because neither creatinine nor BUN can change quickly enough during injury due to the fact that individuals with normal renal function have a functional reserve which compensates for nephron injury (Ding and Mak 2015). The current opinion is that serum creatinine is considered to be a poor indicator of acute renal damage or injury.

Many studies found novel biomarkers that were highly specific to kidney injury as compared to another organ's injury and increases markedly with renal damage earlier than other traditional markers as serum creatinine and urea as KIM-1 (Mårtensson et al., 2012). This biomarker which directly measures injury and can also be easily detected from body fluids like blood or urine can help to monitor injury, and could provide detailed data before the occurrence of late consequences of injury like decrease in GFR.

Strength of this work is the use of blood and urine samples obtained from an ICU hospitalized patient with different symptoms that suggest they may suffer from AKI, and start collecting sample before elevation of the traditional used biomarker creatinine.

This study found that serum creatinine level increased after 48 hour of acute kidney injury by almost one to two folds than normal subjects' value, serum urea and uric acid increased after 24 hour of acute kidney injury by one to two folds than normal subjects' value, serum Albumin decreased after 48 hour of acute kidney injury by one-fold lower than normal subjects' value, microalbuminuria start elevation after 24 hour of acute kidney injury by one to two folds than normal subjects' value, Serum Albumin/ Creatinine ratio start elevation after 24 hour of acute kidney injury by two to three folds than normal subjects' value, Estimated Glomular Filtration Rate

decreased after 48 hour of acute kidney injury by almost one-fold lower than normal subjects' value . 
Both Serum KIM-1 and urine KIM-1 start elevation after 12 hours of admission to Intensive care unit in cases at high risk of acute kidney injury by one-fold than normal subjects' value, while after 24-hour Serum KIM-1 increase by three folds but Urin KIM-1 increase by almost four folds, after 48 hours Serum KIM-1 increase by four folds, but Urin KIM-1 increase seven folds, after 72 hours Serum KIM-1 increase by 5.5 folds but Urin KIM-1 increase by eleven folds, after 96 hours Serum KIM-1 increase by 7 folds, but Urin KIM-1 increase by sixteen folds. .

So in this study both urin and serum kim-1 were noticed to be increased after 12 hours while serum creatinin increase after 48 hours and it was noticed that the rate of elevation and number of folds in urinary kim-1 is higher than serum kim1. Therefore we concluded that kim-1 is better urinary biomarker than measuring its serum value. This elevation may be due to a single transmembrane domain that undergoes membrane-proximal cleavage, which leads to the release of soluble KIM-1 ecto-domain into the urine.

These data are in agreement with previously published data (In et al., 2017), these higher fold difference is enough to make uKIM-1 a better biomarker in urine than serum. The reason of these phenomena is happening because KIM-1 biomarker itself is localized in kidney, exactly in proximal tubule. When the kidney starts to lose its function, the ecto-domain starts to shield out and separated then excreted in urine, so only after 12 hour we will obviously notice a great increase in its urinary levels. Lower increase in serum levels of kIM-1 due to its reabsorption after separation in kidney proximal tubule, or increased genetically translation of this protein due to its role of proximal tubule injury repair people.

In the cases of urine and serum, KIM-1 measured by ELISA kit, their levels after 96 hours increased 7-9 times in serum and 16-18 times in urine than the baseline measurement, while serum creatinine and other traditional measurements maxed out at around 3-5 times the baseline measurements. Serum KIM-1 doesn't have light spot like urine KIM-1 so this study may give a comparing hand in comprising urinary and serum KIM-1 measured by ELISA technique. 55

further studies are needed to give a clear comparison and description of AKI cases by traditional and new biomarkers, which are highly agreed with our data that called a window for new biomarker of AKI. From this window, our following studies will be on genetic expression of KIM-1 molecule . 


\section{$\underline{\text { Conclusion }}$}

We have examined the renal biomarkers nowadays available for an early diagnosis of AKI. The two high-molecular weight bio-markers urine and serum kim-1 are reliable markers in early detection \& diagnosis of AKI .KIM-1 is better urinary biomarker.

Both biomarkers are characterized by being reliable, non-invasive, sensitive, specific, early markers of detecting AKI and before deterioration of patient and before detection of any rise of serum creatinine to decrease mortality and improve outcome of cases when treated early. Therefore, our study recommends using these new biomarkers in prediction and early intervention to treat AKI rather than old traditional biomarkers.

Bihorac A, Chawla LS, Shaw AD, Al-Khafaji A, Davison DL, Demuth GE, et al. (2013). Validation of cell-cycle arrest biomarkers for acute kidney injury using clinical adjudication. Am J Respir Crit Care Med;189:932-9 .

Bonventre JV (2009). Kidney injury molecule-1 (KIM-1): A urinary biomarker an much more. Nephrol Dial Transplant. 24:3265-8

Chaturvedi S, Farmer T, Kapke GF. (2009). Assay validation for KIM-1: human urinary renal dysfunction biomarker. Int J Biol Sci., 5:128-34

Dennen P, Parikh CR (2007): Biomarkers of acute kidney injury: can we replace serum creatinine? Clin Nephrol ; 68:269-78

Ding W., and Mak R.H. (2015). Early markers of obesity-related renal injury in childhood. Pediatric Nephrology 30, 1-4 55

Hirsch R, Dent C, PfriemH, Allen J, Beekman III RH, Ma Q, et al. (2007). NGAL is an early predictive biomarker of contrast-induced nephropathy in children. Pediatr Nephrol; 22(12):2089-95 .

In O. Sun, Sung Hye Shin, A. Young Cho, Hyun Ju Yoon, Mi Yok Chang, Kwang Young Lee1. (2017). Clinical significance of NGAL and KIM-1 for acute kidney injury in patients with scrub typhus. Plos one 12, 1-11

Martensson J, Bell M, Oldner A, Xu S, Venge P, Martling CR. (2012). Neutrophil

gelatinaseassociated lipocalin in adult septic patients with and without acute 
kidney injury. Intensive Care Med; 36(8):1333-40.

Rees J, Kain R. (2008): KIM-1/Tim-1 from biomarker to therapeutic target. Nephrol Dial Transplant., 23:3394-6.

Shao Z, et al. (2014). Crystal structure of tRNA m1G9 methyltransferase Trm10: insight into the catalytic mechanism and recognition of tRNA substrate. Nucleic Acids Res 42(1):509-25 
Medicine Updates

Faculty of medicine

April 2020,volume 1, issue 1 https://muj.journals.ekb.eg dean@med.psu.edu.eg vice_dean_postgraduate@med.psu.edu.eg

DOI: $10.21608 / \mathrm{muj} .2020 .25068 .1001$

ISSN : 2682-2741

Submitted: $25 / 1 / 2020$

Accepted : 13/3/2020

Pages:68-71

\section{MRI of male breast carcinoma}

Carmen ali ahmed, lecturer of radiodiagnosis faculty of Medicine port said Universty Egypt.

\section{$\underline{\text { Abstract }}$}

MRI breast is designed to diagnose breast cancer in female. MRI has a great role in diagnosis of early breast cancer. MRI has a great role in differentiation between postoperative scar and post-operative recurrence in cases of surgically removed cancer breast. MRI also used in follows up the response of chemotherapy in cases of advanced breast cancer. Few literatures explain the use of MRI in male breast cancer. In this case report we present a case of male breast cancer and demonstrate MRI characters, enhancement and diffusion patterns similar to that occur in female breast cancer. In our case report we concluded that MRI morphologic features of cancer breast in male were the same MRI morphologic features of cancer breast in female. Cancer breast in male showed the same enhancement kinetic similar to that occurred in female with cancer breast. Cancer breast in male showed a similar enhancement curves like that in female with breast cancer. Cancer breast in male has the same diffusion patterns that occur in female with cancer breast.

Abbreviations: $\mathrm{MRI}$, magnetic resonance imaging 


\section{Case report:}

Male patient aged 48 years presented by palpable lump in the right breast axillary tail

Contrast-enhanced magnetic resonance imaging performed to the patient. Dynamic post-contrast T1 subtraction image (figure 1) showed irregular shaped mass in the axillary tail of the right breast. The mass was irregular shape with homogenous enhancement. The mass showed type 3 (washout) dynamic curve (figure 2). In diffusion weighted image (figure 3) the mass was high signal intensity denoting restricted diffusion with low ADC value 0.81 $\times 10^{-3} \mathrm{~mm}^{2} / \mathrm{sec}$ in ADC map (figure 4). This mass was categorized as BI-RADS 5 Core biopsy revealed a grade III, invasive ductal carcinoma.

\section{Discussion}

Breast cancer in male is rare. Male breast cancer occurs in only $1 \%$ of all breast cancers $(1,2)$

In the past mammography was used for early diagnosis of breast cancer in male, the mammographic features of cancer breast in male were similar to those found in breast cancer in female (3).

The most important imaging modality for diagnosis of cancer breast in male is Ultrasound. Ultrasound has a great role in evaluation of male breast cancer; it also shows the same features like those seen in the female with breast cancer (3).

In our case report we concluded that MRI morphologic features of cancer breast in male were the same MRI morphologic features of cancer breast in female. Cancer breast in male showed the same enhancement kinetic similar to that occurred in female with cancer breast. Cancer breast in male showed a similar enhancement curves like that in female with breast cancer. Cancer breast in male has the same diffusion patterns that occur in female with cancer breast. 

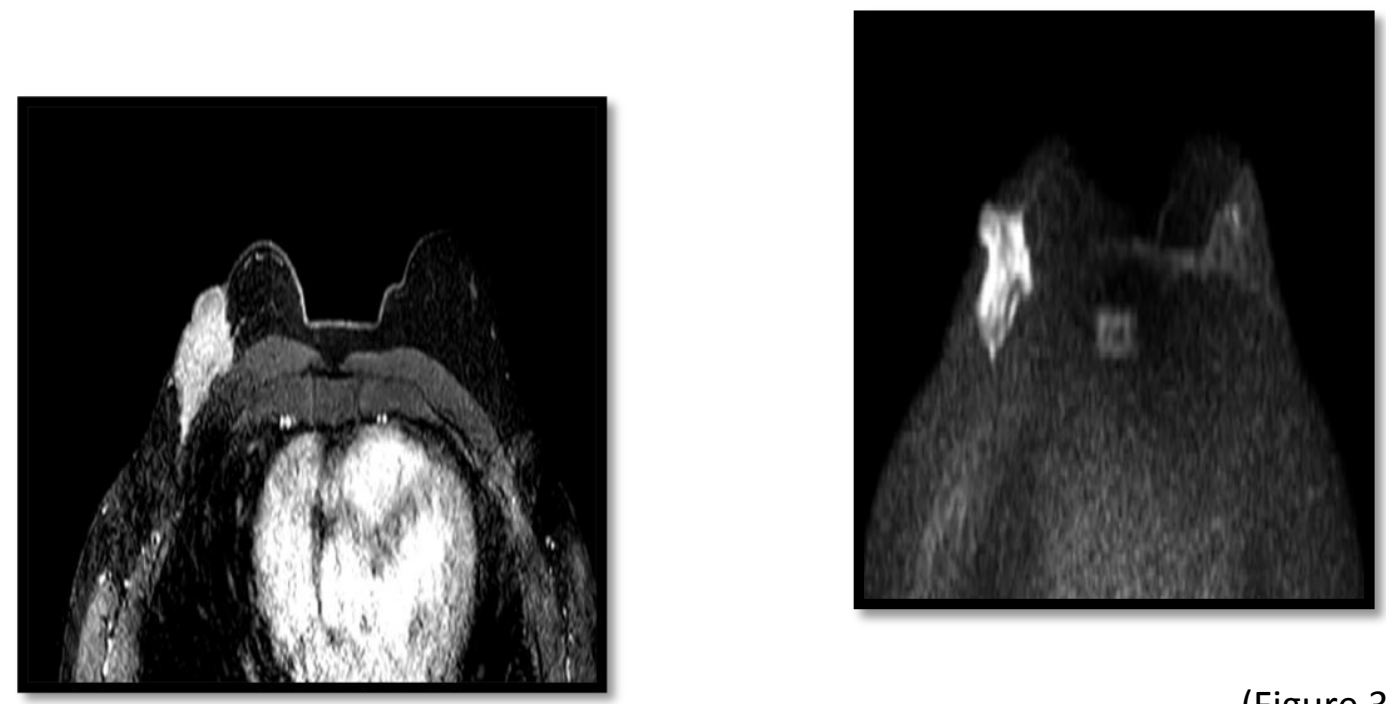

(Figure 3)

(Figure 1)
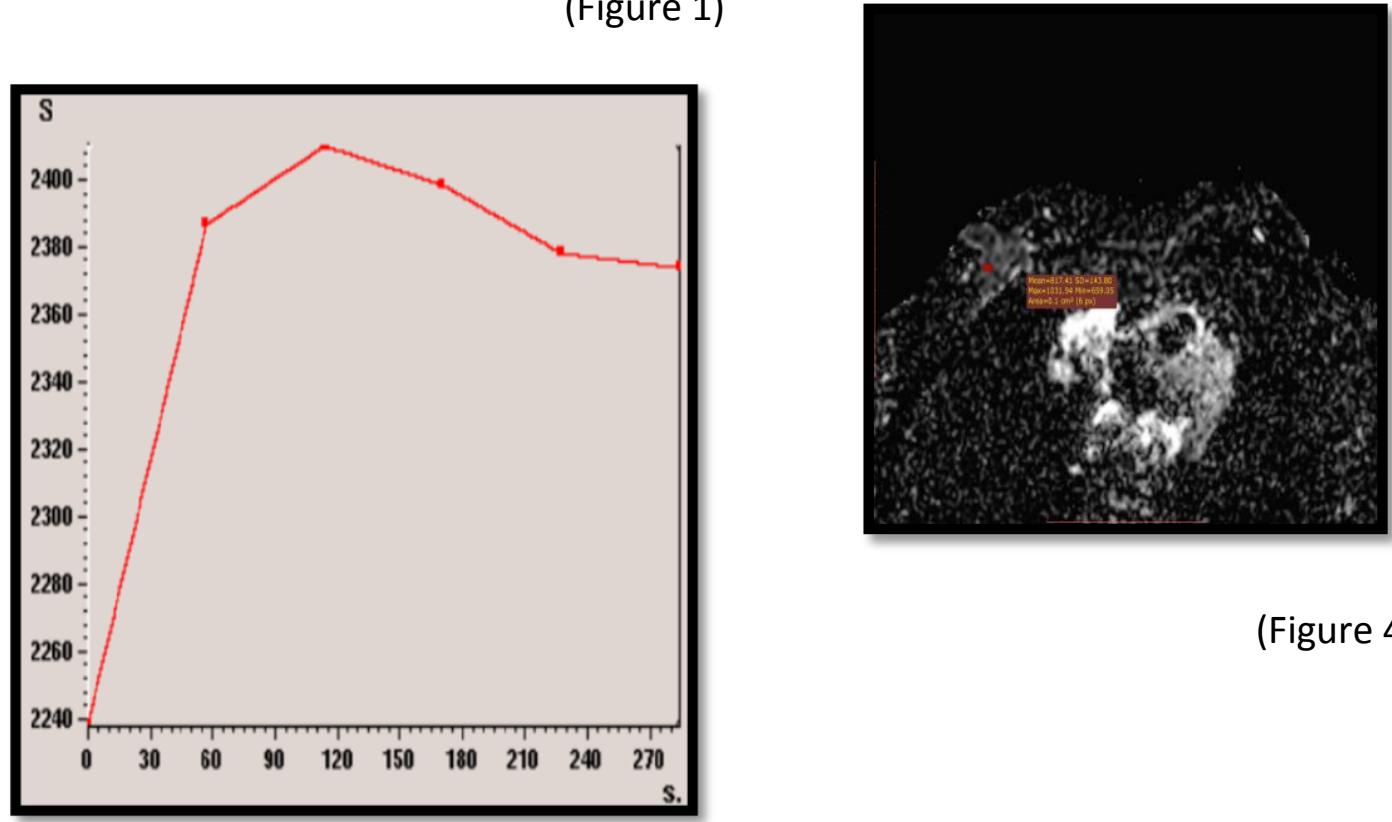

(Figure 4)

(Figure 2) 


\section{$\underline{\underline{\text { References }}}$}

1. Landis SH, Murray T, Bolden S, Wingo PA. Cancer statistics, 1999. CA Cancer J Clin. 1999;49:8.

2. Weiss JR, Moysich KB, Swede H. Epidemiology of male breast cancer. Cancer Epidemiol Biomarkers Prev. 2005;14(1):20-26.

3. Shaw A, Smith B, Howlett D. Male breast carcinoma and the use of MRI. 2011: Radiology Case Rep. 2011; 6(3): 455. 

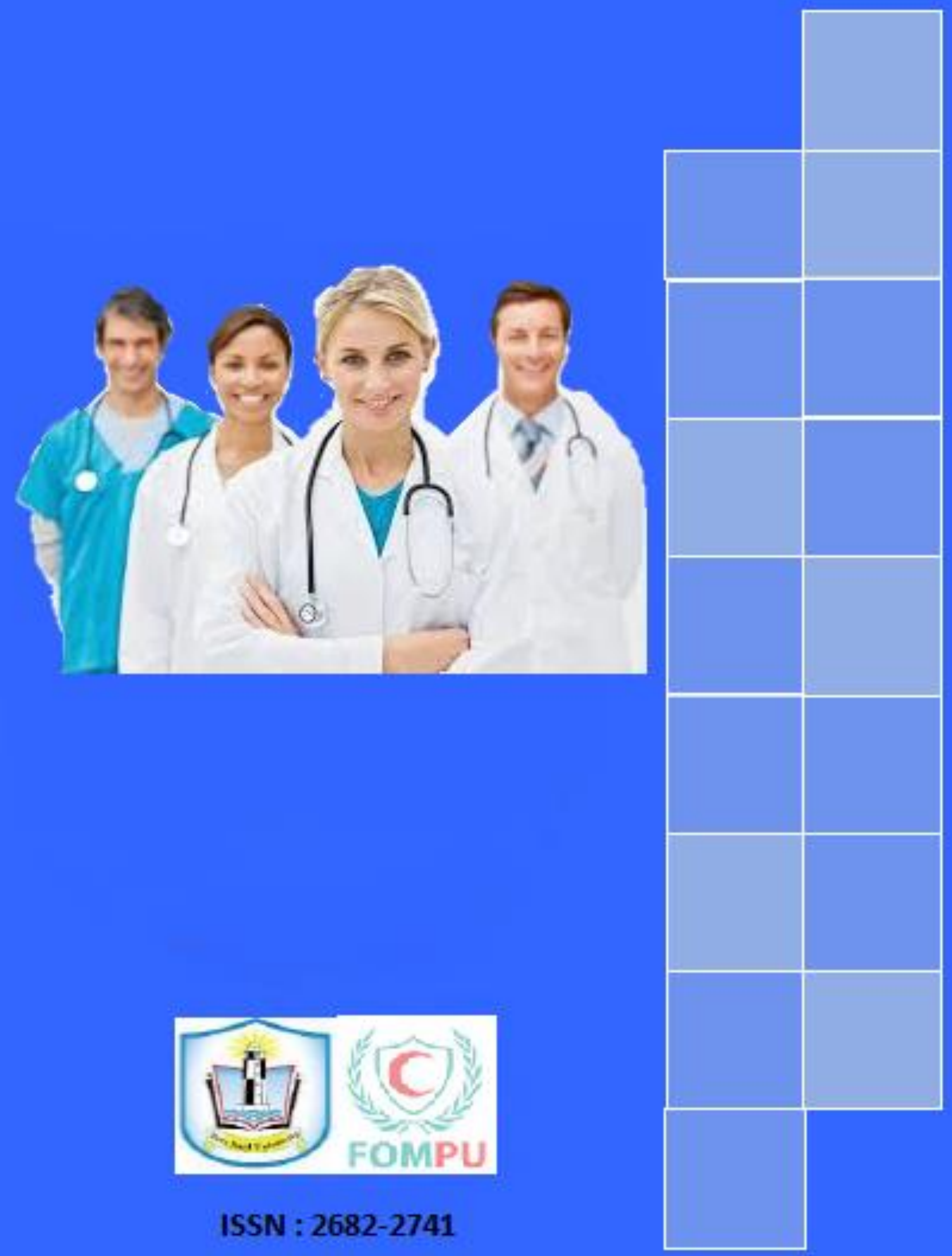

ISSN : 2682-2741 